\title{
Molecularly imprinted polymer-based potentiometric sensors
}

\author{
Junhao Wang a, c, Rongning Liang a, d, **, Wei Qin ${ }^{\text {a, b, d, * }}$ \\ a CAS Key Laboratory of Coastal Environmental Processes and Ecological Remediation, Yantai Institute of Coastal Zone Research (YIC), Chinese Academy of \\ Sciences (CAS), Shandong Key Laboratory of Coastal Environmental Processes, YICCAS, Yantai, Shandong, 264003, PR China \\ ${ }^{\mathrm{b}}$ Laboratory for Marine Biology and Biotechnology, Pilot National Laboratory for Marine Science and Technology, Qingdao, Shandong, 266237, PR China \\ ${ }^{c}$ University of Chinese Academy of Sciences, Beijing, 100049, PR China \\ ${ }^{\mathrm{d}}$ Center for Ocean Mega-Science, Chinese Academy of Sciences, Qingdao, Shandong, 266071, PR China
}

\section{A R T I C L E I N F O}

\section{Article history:}

Available online 9 July 2020

\section{Keywords:}

Molecularly imprinted polymer

Polymeric membrane potentiometric sensor

Organic molecules

Biological species

Recent advances

Research directions

\begin{abstract}
A B S T R A C T
Carrier-based polymeric membrane potentiometric sensors have been widely used for determination of inorganic ions in clinical and environmental applications. In view of the need for a wider application scope of these sensors, the list of targets needs to be increased. Molecularly imprinted polymer (MIP)-based potentiometric sensors are ideal candidates for sensing of organic and biological species. The development of such sensors may open attractive horizons for potentiometric sensing and further expand the field. The past few decades have witnessed remarkable achievements in these sensors. This review summarizes recent advances in the MIP synthesis, the detection modes of these sensors and their applications for organic and biological species in environmental and biological analyses, and attempts to illustrate the research directions. We hope that this review will shed new light on the understanding of MIP-based potentiometric sensors and pave the way for the widespread applications of polymeric membrane potentiometric sensors.
\end{abstract}

(c) 2020 Elsevier B.V. All rights reserved.

\section{Introduction}

Currently, the ionophore-doped solvent polymeric membrane ion-selective electrodes (ISEs) play an important role in various fields including clinical diagnosis, environmental monitoring and food analysis due to their excellent selectivity, easy preparation and high reliability $[1,2]$. It has been estimated that each year over a billion measurements with the ISEs are performed globally in clinical laboratories alone [3]. The principle of these electrodes is based on converting the activity of the target ion into a potential, and then quantifying the ion activity according to the Nernst equation. Ionophores are crucial to the sensitivity and selectivity of the ISEs, which can form stable complexes with the target ions via

\footnotetext{
* Corresponding author. CAS Key Laboratory of Coastal Environmental Processes and Ecological Remediation, Yantai Institute of Coastal Zone Research (YIC), Chinese Academy of Sciences (CAS); Shandong Key Laboratory of Coastal Environmental Processes, YICCAS, Yantai, Shandong, 264003, PR China. Fax: +86-535-2109000. ** Corresponding author. CAS Key Laboratory of Coastal Environmental Processes and Ecological Remediation, Yantai Institute of Coastal Zone Research (YIC), Chinese Academy of Sciences (CAS); Shandong Key Laboratory of Coastal Environmental Processes, YICCAS, Yantai, Shandong, 264003, PR China. Fax: +86-535-2109000.

E-mail addresses: rnliang@yic.ac.cn (R. Liang), wqin@yic.ac.cn (W. Qin).
}

the selective ion-ligand interaction [4,5]. Over the past decades, lots of ionophores have been synthesized and even commercially available. However, note that, these ionophores are mostly used for determination of inorganic ions (e.g., electrolyte ions and heavy metal ions). So far, the synthetic receptors for selective recognitions of organic and biological species are still rather rare.

As highly suitable receptors for organic and biological species, molecularly imprinted polymers (MIPs) have attracted considerable attention in chemical sensors because they possess similar affinities and selectivities with the natural receptors such as antibodies and enzymes [6,7]. Especially, MIPs are stable, less costly and easier to produce compared to their biological counterparts [8]. Generally, these polymers are synthesized by copolymerization of the functional monomers, the template molecules and the crosslinking agents in the porogenic solvents through covalent or noncovalent methods. The functional monomers carry the functional groups for the template recognition and the crosslinking agents fix the binding sites firmly in the desired structures. After template removal by the solvents (e.g., methanol and acetic acid), the recognition cavities complementary to the template molecules in shape and size are formed, which can selectively rebind the target molecules $[9,10]$. The non-imprinted polymers (NIPs) are usually prepared under identical conditions except for omission of the 
template. However, the NIPs which also contain the functional groups do not exhibit specific recognition ability towards the templates. This can confirm that the selectivity of the polymer is mainly determined by the MIP cavity.

During the past few decades, many MIPs have been utilized as the selective receptors to fabricate potentiometric sensors. The typical fabrication processes for the MIP-based polymeric membrane potentiometric sensors are shown in Fig. 1. Fig. 1a represents a fabrication process for a conventional sensor based on the incorporation of the MIP receptor in the polymeric sensing membrane. Such process usually involves two steps. The first is the synthesis of the MIP receptor. Until now, several methods have been applied to synthesize these receptors such as the bulk, precipitation or surface imprinting technique. The resultant MIP receptors include MIP microbeads, nanobeads, and amorphous particles [11]. The second is the fabrication of a potentiometric sensor. In general, the MIP is incorporated into the polymeric membrane to function as the conventional ionophore of the ISE [12]. The obtained membrane electrode is finally electrically contacted to a potentiometer with a reference electrode for electromotive force (EMF) measurements. For the MIP coated polymeric membrane potentiometric sensor (Fig. 1b), the preparation procedures are different from those of the conventional one. The sensing membrane usually contains two layers: the surface MIP recognition layer for the target and the potentiometric transduction layer for the indicator ion. The former is fabricated on the surface of the latter by the surface molecular imprinting technique [13]. Chronopotentiometry is applied to directly monitor the blocking effect induced by the surface recognition. A three-electrode cell comprising the MIP-based electrode as the working electrode, the reference electrode and the auxiliary electrode is employed for the chronopotentiometric measurements. For the electropolymerized MIP-based potentiometric sensor, a conductive polymer layer is firstly formed or coated upon an electrode substrate in the presence of the template by applying a fixed potential/current (Fig. 1c) [14]. After electro-polymerization, the template is then removed by the classical solvent extraction or electrochemical oxidation. Other potentiometric measurement steps are similar to those of the conventional one.

The response mechanism of the fabricated ISE sensing mode is based on classical potentiometry (Nernst equation-based potentiometry) or non-classical potentiometry (i.e., dynamic potentiometry). Nowadays, MIP-based potentiometric sensors have been successfully used for potentiometric detection of organic ions, neutral organic species and biological species related with clinical and environmental applications [15,16]. These spectacular advances have facilitated new applications for which potentiometric sensors have not been used conventionally.

This review summarizes recent progress in the development and the applications of solvent polymeric membrane potentiometric sensors based on the MIP receptors, including the synthesis methods of the MIPs, the transduction mechanism, the applications and the new development trends of these sensors. We hope that the issues discussed will shed new light on the understanding of MIP-based potentiometric sensors and pave the way for the widespread applications of the polymeric membrane ISEs, especially in organic and biological species related with clinical and environmental aspects.

\section{Syntheses of MIPs for potentiometric sensors}

Compared to the MIP materials for chromatographic separation, the MIPs for sensor fabrication are generally synthesized by more delicate approaches. Usually, there are two main methods for synthesis of the MIPs: the covalent and non-covalent imprinting methods. Compared to the non-covalent interaction, the covalent one is more stable and more stoichiometric, which can lead to a higher selectivity and less non-specific binding sites. However, it also suffers from the problem that guest binding and guest release are slow since covalent imprinting involves the formation and breakdown of a covalent linkage. At present, non-covalent imprinting is

(a)
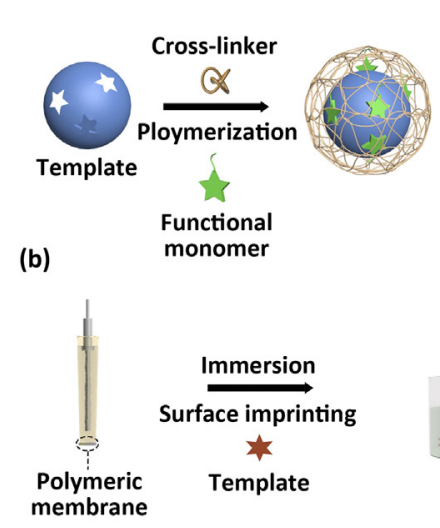

(c)

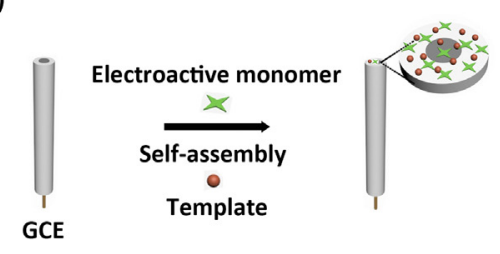

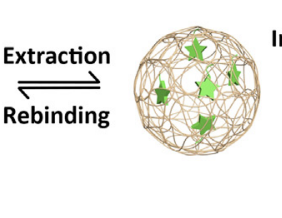
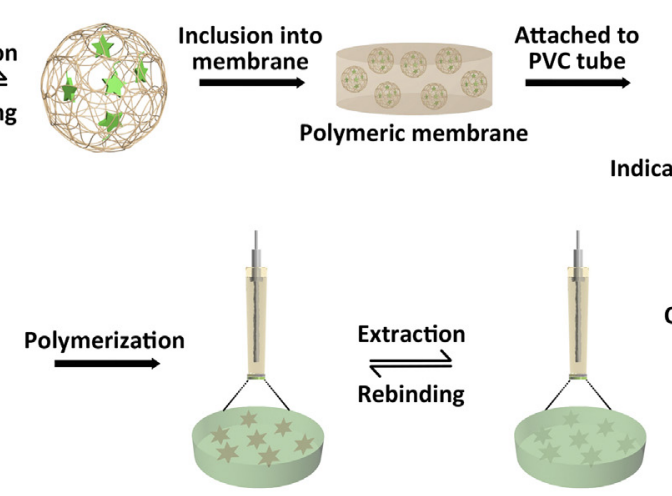

Chronopotentiometric

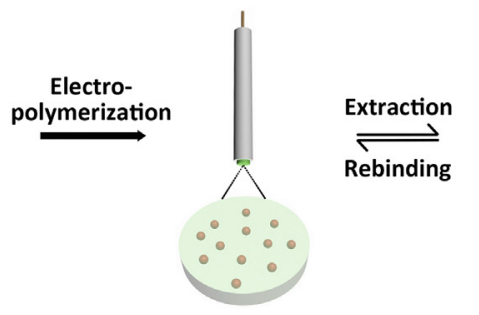

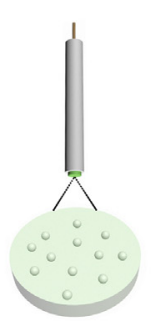
detection
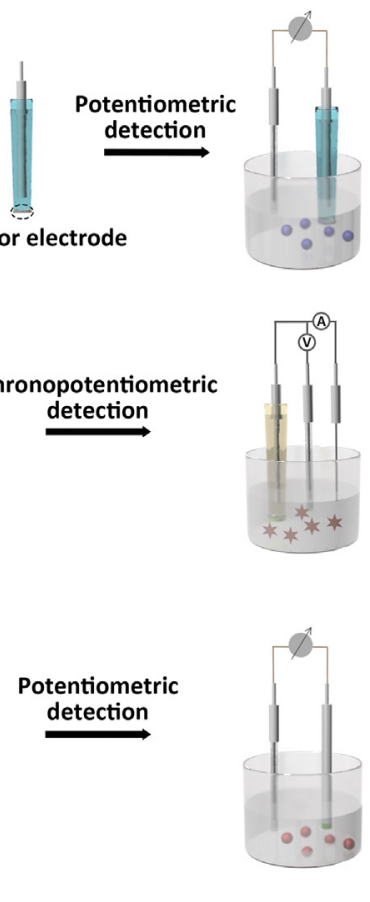

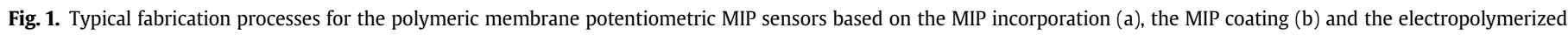
MIP (c). 
still the most popular and general synthesis strategy for preparing the MIP receptors in potentiometric sensors due to the simplicity of operation and the rapidity of template binding and removal although its monomer-template adduct is labile and not strictly stoichiometric. Semi-covalent imprinting combines the durability of covalent imprinting and the rapid target binding of non-covalent imprinting. The semi-covalent approach shows strong template binding and efficient rebinding. However, the application of this approach is restricted by some limitations. For example, the covalent bond formed between monomer and template should be strong enough to withstand the polymerization conditions [17-19].

For the polymeric membrane ISEs, the incorporation of the MIP receptors into the plasticized ISE membrane usually requires consideration of their existing forms (soluble or dispersed) in the polymeric membrane matrix, which is vital for the selectivity and the sensitivity of potentiometric sensors. Note that, since the MIPs receptors are usually rigid and highly cross-linked polymers, most of them cannot be easily dissolved but rather be dispersed in the plasticized membranes. There is only one dissolved MIP receptor which is synthesized by the swelling of the traditional MIP at a high temperature [20]. In this work, it has been found that the detection sensitivity of the insoluble MIP electrode is much lower than that of the electrode based on the soluble MIP (e.g., for bisphenol AF, $1.32 \mathrm{mV} / \mu \mathrm{M}$ vs $4.93 \mathrm{mV} / \mu \mathrm{M})$. Also, the sensor based on the soluble MIP exhibits a more excellent selectivity as compared to that using the traditional insoluble MIP. These remarkable improvements in sensitivity and selectivity could be attributed to the fact that the soluble MIP beads can be well dissolved in the polymeric sensing membrane, thus inducing more available binding sites in the membrane. Up to now, several methods have been proposed to prepare the MIP receptors of the ISEs, such as bulk polymerization, precipitation polymerization, surface imprinting and electro-polymerization.

\subsection{Bulk polymerization}

Bulk polymerization is a popular and commonly used method to prepare the MIP receptors due to its rapidity and ease of operation $[19,21]$. The typical synthesis procedure for bulk polymerization is illustrated in Fig. 2. In general, except for the classical MIP synthesis procedures including pre-polymerization of the functional monomer and the template, polymerization and template removal, the obtained block polymers are usually broken to pieces, ground and sieved after polymerization.

A melamine MIP was synthesized by the bulk polymerization method. It was based on melamine as the template, methacrylic acid as the functional monomer and ethylene glycol dimethacrylate as the cross-linking agent, respectively [12]. The obtained MIP was then incorporated into the ISE membrane matrix to construct a polymeric membrane potentiometric sensor for detection of melamine. The membrane electrode showed a nearNernstian response ( $54 \mathrm{mV} /$ decade) to the protonated melamine over the concentration range of $5.0 \times 10^{-6}$ to $1.0 \times 10^{-2} \mathrm{~mol} / \mathrm{L}$. In addition, the electrode showed an excellent selectivity over other inorganic cations such as $\mathrm{Na}^{+}$and $\mathrm{K}^{+}$. However, the selectivity over the organic cations with the structures similar to that of melamine was not investigated. Sales et al. [22] used aniline as the functional monomer and acetylcholine as the template to prepare the MIP receptor through bulk polymerization. A resultant potentiometric sensor with a detection limit of $3.45 \times 10^{-5} \mathrm{~mol} / \mathrm{L}$ was obtained. A poor selectivity over some potential interfering species (e.g., creatine and cysteine) was observed for the ISE based on the MIP synthesized by bulk polymerization. Moxifloxacin-imprinted polymers synthesized via bulk polymerization were introduced by Wagdy et al. and were applied as the recognition receptor of a potentiometric sensor. The detection limit for moxifloxacin was $1.7 \times 10^{-6} \mathrm{~mol} / \mathrm{L}$ [23]. The moxifloxacin MIP-based potentiometric sensor also exhibited a poor selectivity over other interferents such as glycine and phenylalanine. It should be noted that, for bulk polymerization, the grinding procedure can result in polymer particles of irregular size and shape, which may have a negative influence on recognition efficiency (e.g., inefficient heterogeneous interactions and low-affinity target binding) and further lead to poor sensing performance of potentiometric sensors in terms of selectivity and sensitivity [24]. This poses serious limits to the wide use of this synthesis method.

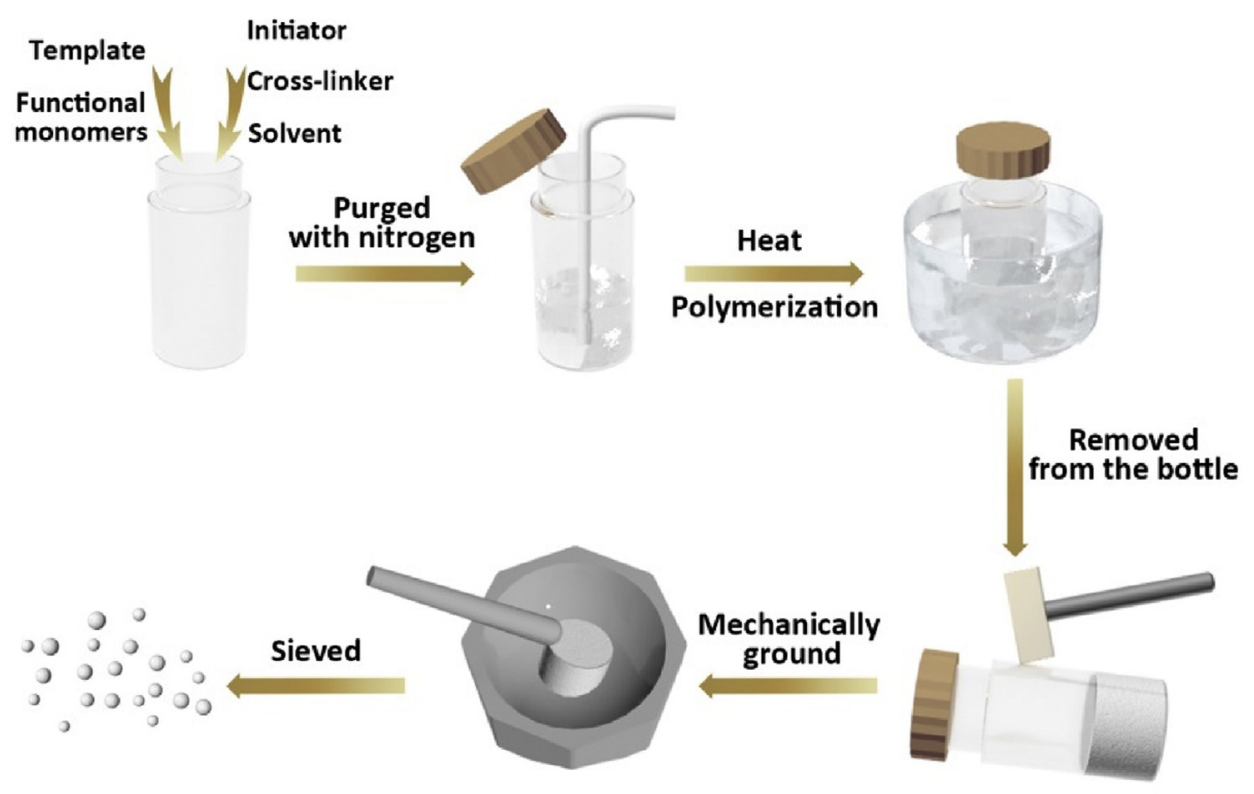

Fig. 2. Typical synthesis process of the MIPs via bulk polymerization. 


\subsection{Precipitation polymerization}

In order to overcome the drawbacks of bulk polymerization, precipitation polymerization which is a most promising approach to produce high-quality, uniform and spherical imprinted polymers has been proposed. The synthesis process for precipitation polymerization is shown in Fig. 3. Compared to bulk polymerization, a larger amount of the organic porogen solvents is involved in precipitation polymerization [25]. The polymer chain precipitates out of the solvent in the growing process to form the uniformed microspheres [19].

Very recently, a MIP-based potentiometric sensor based on covalent recognition was developed by Qin et al. [26]. The boronate-affinity MIP was used as the selective receptor, which could covalently bind with a cis-diol containing compound. By using catechol as a model, the proposed sensor exhibited a more excellent reversibility than the conventional MIP sensor based on non-covalent interaction.

Qin et al. also demonstrated that the membrane ISE containing the uniform MIP beads prepared by precipitation polymerization shows a much shorter response time (ca. 2 min) than that with irregular particles synthesized by bulk polymerization ( $c a .6 \mathrm{~min}$ ) [24]. Moreover, much lower levels of noise were observed for the potential response with uniform polymer beads. These observations might be attributed to the fact that the uniform beads can be well dispersed in the polymeric ISE membrane, thus causing more available binding sites in the membrane and lower membrane impedance as compared to the membrane prepared with irregular particles. In addition, the bisphenol $S$-imprinted polymer [27] and the 2-naphthoic acid-imprinted polymer [28] prepared via precipitation polymerization further prove that the uniform-sized MIP nanobeads have better dispersion ability in the PVC membrane than the uniform MIP microbeads and potentiometric sensor exhibits a better response performance. For 2-naphthoic acid detection, the MIP nanobead-based sensor exhibited a Nernstian response over the concentration range of $1.0 \times 10^{-5}$ to $3.0 \times 10^{-4} \mathrm{~mol} / \mathrm{L}$, while the electrode with the MIP microbeads deviated obviously from the Nernstian response at the same concentration range.
It has been well established that the highly cross-linked MIP receptors can only be dispersed in the polymeric membranes [29]. In order to overcome this, Qin and coworkers proposed a soluble MIP receptor which can be well dissolved in the polymeric sensing membrane [20]. The preparation process of the soluble MIP was based on the swelling of the conventional MIP synthesized by precipitation polymerization at a high temperature in the presence of a swelling solvent. Experiments showed that potentiometric sensor based on the soluble MIPs exhibited a much higher sensitivity compared to that based on the conventional MIPs.

\subsection{Surface imprinting}

Nowadays, imprinting of macromolecules such as proteins, cells and virus still remains a challenge since the traditional MIPs are highly cross-linked, making it difficult for macromolecules to reach the binding sites buried in the interior of the MIPs. The surface imprinting technique offers a unique protocol for macromolecules imprinting compared to the traditional imprinting method. It exhibits excellent features such as high selectivity, accessible binding sites, and fast association/dissociation kinetics since the template-imprinting sites situate at the surface or in the proximity of polymer's surface [19]. Surface imprinted polymers created by self-assembly typically follow the strategy shown in Fig. 4. In the similar way with classical molecular imprinting, the templates (e.g., lipopolysaccharides, nucleotides, proteins, virus, bacteria, cells) are mixed with the monomers (e.g., acrylamide, methacrylic acid, silane, dopamine), the cross-linkers and the initiators on the surface of the substrate (e.g, the PVC membrane) [30-33]. During polymerization, the template interacts with the monomers through covalent or non-covalent interactions. After template removal, the surface imprinted polymer is formed and the specific surface recognition sites are generated that are accessible for the templates.

Qin et al. proposed a simple and facile approach to fabricate the surface imprinted layer on the surface of the ISE sensing membrane by using the polydopamine coating [13]. The sensing membrane was composed of two layers: the surface recognition layer for the biospecies (the polydopamine layer) and the potentiometric

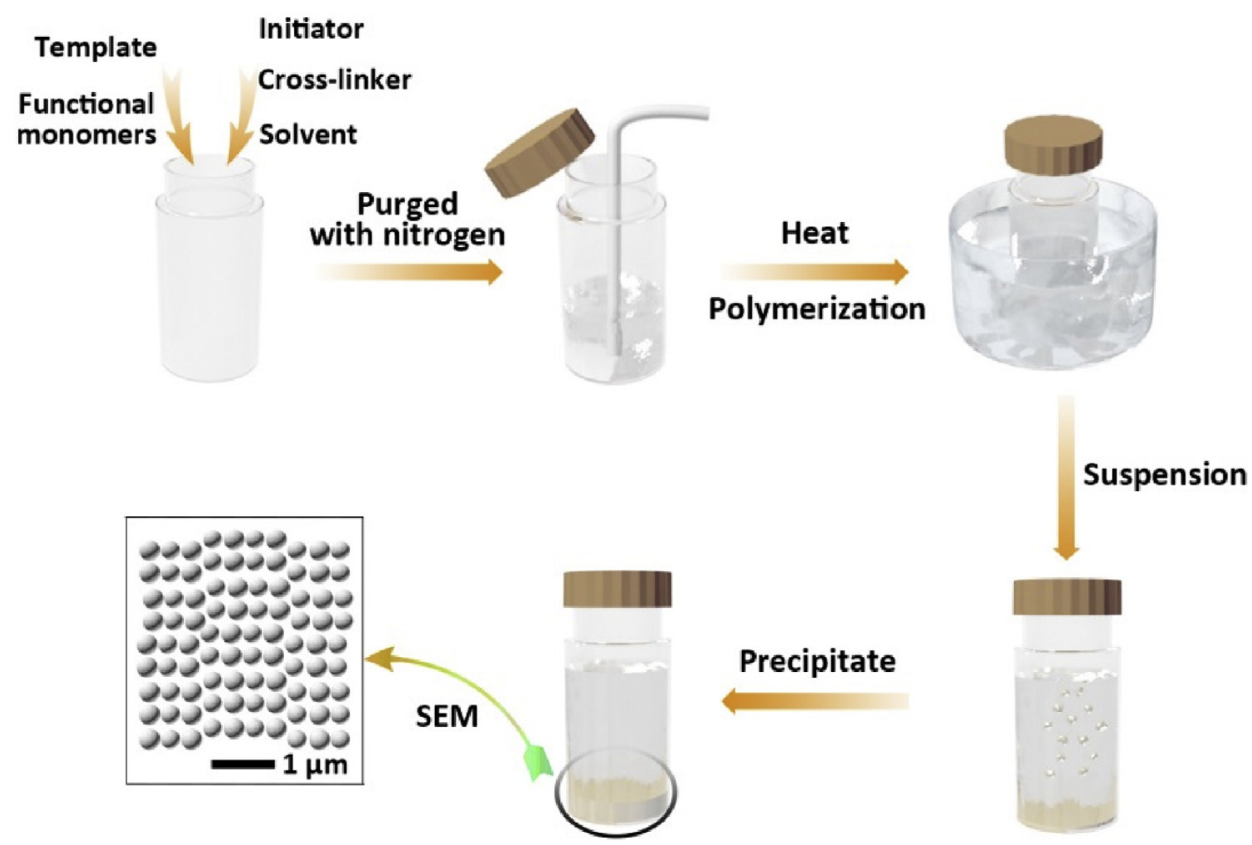

Fig. 3. Typical synthesis procedures of the MIPs via precipitation polymerization. 


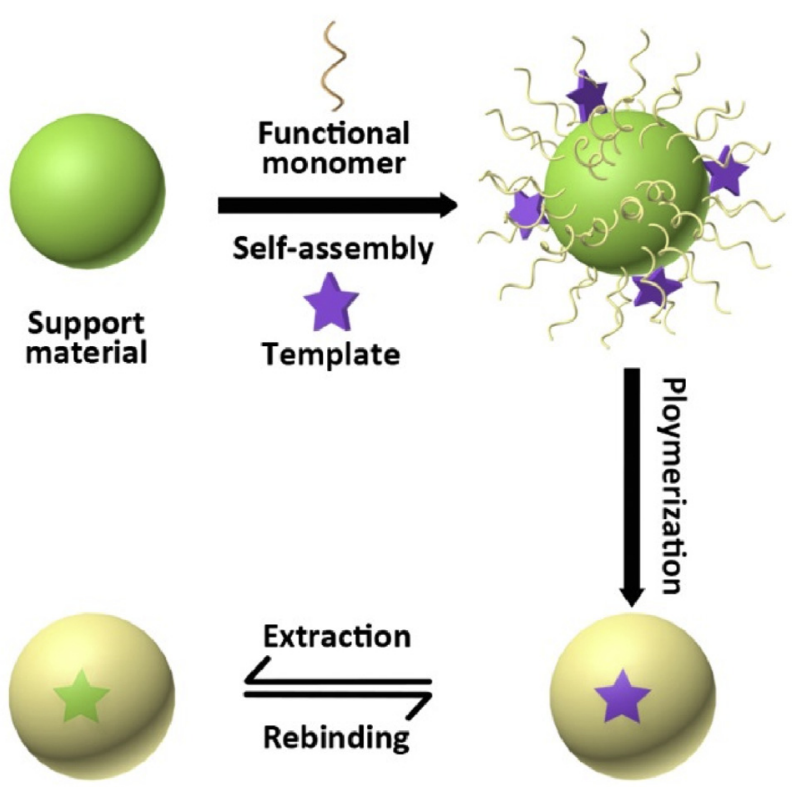

Fig. 4. Synthesis process for surface imprinting. The template is mixed with the polymerization mixture containing the monomers, the cross-linkers, and the initiators on the surface of the supported substrate. During polymerization, the template in teracts with the monomer through covalent or non-covalent interactions. After template removal, the binding sites are situated at the surface or in the proximity of the polymer's surface.

transduction layer for the indicator ion (the plasticized PVC ionselective membrane). Such polydopamine layer not only serves as a surface imprinted layer for bioanalyte recognition but also works as an ion transport blockage for indicator ion transfer. Additionally, such coating has plenty of non-covalent functional group such as amino group and hydroxy group as well as $\pi-\pi$ bonds. These groups exactly match the characteristics of the MIPs for efficient recognition. In addition, such a coating layer can be deposited on any substrate surface by simple immersion of the substrate in a dopamine solution at a weakly alkaline $\mathrm{pH}$. This mild polymerization condition can effectively avoid the irreversible biospecies inactivation in the imprinting process.

Barrio and coworkers [34] synthesized histamine MIP nanoparticles by using the solid-phase imprinting method. In this method, the template was covalently immobilized on the surface of a solid support (e.g., glass beads). Polymerization was initiated under conditions that promote the formation of polymer nanoparticles rather than macrogels or monoliths. The advantage of this method is that all binding sites have the same orientation and are located at the surface of the particle, which can improve the homogeneity and the accessibility of the binding sites [35,36]. They compared the performance of the MIP-based potentiometric sensor obtained by solid-phase imprinting and bulk polymerization. It has been found that the MIP-based membrane exhibited a linear Nernstian response over the concentration range of $10^{-6}$ to $10^{-2} \mathrm{~mol} / \mathrm{L}$ with a detection limit of $1.12 \times 10^{-6} \mathrm{~mol} / \mathrm{L}$. However, their attempts to compare two kinds of ISEs based on the histamine MIPs (one with the proposed MIP nanoparticles as the receptors and the other with the MIP microparticles prepared by bulk polymerization) were unsuccessful because the response of the microparticle-based electrode was rather irreproducible. Piletska et al. [37] also applied a similar method to prepare MIP nanoparticles which are used as the receptors to fabricate potentiometric sensor for cocaine detection. The detection limit of fabricated potentiometric sensor was $6.0 \times 10^{-10} \mathrm{~mol} / \mathrm{L}$.

In addition to conventional free radical polymerization, surface imprinting can also be achieved via living/controlled radical polymerization. Such polymerization method firstly immobilizes an initiator on the surface of the substrate, and then a polymer film is grown on by photonic or thermal initiation [38]. In recent years, the reversible addition-fragmentation chain transfer (RAFT) technique has become wide acceptance in living/controlled radical polymerization owing to their attractive features such as wide application range of monomers, simple operation and without the need of organometallic catalysts [39]. This technique allows for the control over the MIPs construction, including structure, chemical composition and thickness of the MIP layer. Thus, distribution homogeneity of the binding sites, the template recognition ability and the diffusion rate of template molecules across the polymer membrane can be improved. Barrio's group described a novel thiolcompound as a trigger-transfer-terminator which was immobilized on the surface of the gold microelectrode to control the growth of the MIP. The proposed MIP could be used for selective recognition of 4-ethylphenol [40]. The developed microsensor based on the MIP was linear in the concentration range of $1.0 \times 10^{-6}$ to $1.0 \times 10^{-3} \mathrm{~mol} / \mathrm{L}$.

\subsection{Electro-polymerization}

Electro-polymerization is also an efficient method for preparing the MIP receptors. In the preparation of the MIP film, the electroactive monomers and the templates are self-assembled on the surface of the electrode substrate through covalent or noncovalent interactions [41]. When the electroactive monomers are polymerized on the electrode surface by the applied current or potential, the template molecules are embedded in the polymer film, thereby introducing selective recognition sites into the polymer film. Compared to other polymerization methods, electro-polymerization exhibits some specific merits. A polymer film with a desired thickness can be obtained by controlling the number of the applied electro-polymerization cycles. In addition, such polymerization method provides a simple and rapid technique to fabricate an adherent film which cannot easily peel off from the electrode substrate. Hutchins and Bachas reported a $\mathrm{NO}_{3}^{-}$-imprinted ISE prepared by electropolymerizing pyrrole onto a glassy carbon electrode in the presence of $\mathrm{NaNO}_{3}$ [42]. A film was produced with pores that were complementary to the size of the targeted analyte ion. Both the pore size and the charge distribution within the polymerized film formed a recognition cavity for $\mathrm{NO}_{3}^{-}$, which provided a selectivity superior to those of the conventional $\mathrm{NO}_{3}^{-}$-selective electrodes. The selectivity coefficients of the polypyrrole-based $\mathrm{NO}_{3}^{-}$-selective electrodes for $\mathrm{NO}_{3}^{-}$over $\mathrm{Cl}^{-}, \mathrm{ClO}_{4}^{-}, \mathrm{SCN}^{-}$and $\mathrm{I}^{-}$were $5.7 \times 10^{-2}, 5.7 \times 10^{-2}, 3.6 \times 10^{-1}$ and $5.1 \times 10^{-2}$, respectively. In order to obtain a higher degree of crosslinking that is expected to improve the selectivity, Murray et al. used $\mathrm{N}$-methyl pyrrole as the monomer to synthesize the $\mathrm{NO}_{3}^{-}$-imprinted polymer via electro-polymerization [43]. The obtained ISE based on the $\mathrm{NO}_{3}^{-}$-imprinted polymer exhibited a linear potential response between the concentration range of $5.0 \times 10^{-6}$ to $1.0 \times 10^{-1} \mathrm{~mol} / \mathrm{L}$ with a near-Nernstian response slope of $-56.3 \mathrm{mV} /$ decade. Tonelli et al. introduced an ascorbate potentiometric sensor fabricated by using a glassy carbon electrode modified with a film of polypyrrole electropolymerized in the presence of ascorbate [44]. The sensor was successfully used for determination of vitamin $\mathrm{C}$ in commercial beverages and pharmaceutical samples with recoveries of $c a .100 \%$.

Note that, in these previous works, the conductive polypyrrole polymer was used as the MIP matrix since the non-conductive polymer polypyrrole is unsuitable for the fabrication of the sensing membrane of the ISE because of its high impedance. In addition, it has been reported that, during overoxidation, polypyrrole loses its electroactivity due to ejection of dopant, and 
oxygen containing groups such as carbonyl and carboxylate will be introduced to the pyrrole unit. The high electron density of the carbonyl group may act as a barrier to hinder the diffusion of the anions in the film. Overoxidation in the pyrrole ring can lead to effective rejection of the anionic species and preferential collection of the cationic species. Hence, the conductive polypyrrole polymer is usually employed to fabricate the ISE membrane [14,41,44].

\section{Detection modes of the MIP-based potentiometric sensors}

\subsection{Classical potentiometry}

Classical potentiometry is typically referred to the Nernst equation-based potentiometric methods, in which the potential is as a function of the activity of the analyte in the sample solution [45-48]. When an MIP is used as a receptor, it is expected that such receptor can function as the same as the classical ionophore. The MIP can act as a new type of ionophore to enhance the selectivity of the ISEs by specific binding of the ion of interest via host-guest interactions (e.g., hydrogen-bonding, electrostatic and apolar interactions). The phase boundary potential is generated by the extraction effect of the MIPs in the polymeric membrane with the ions from the solution phase into the membrane phase [45,47]. Fig. 5 shows a schematic view of the equilibrium between the sample and the ISE membrane containing a MIP receptor for classical potentiometry. In this classical potentiometric mode, the electrode should be conditioned by the primary ions (e.g., organic ions) before measurements. The organic ion transfers from the aqueous phase into the hydrophobic membrane phase and forms the stable complex with the MIP in the hydrophobic ISE membrane. After each measurement, the reuse can be simply achieved by washing the electrode with deionized water after each measurement. Up to now, based on classical potentiometry, various organic ions (e.g., melamine, ciprofloxacin, oxytetracycline and dinotefuran) have been potentiometrically determined.

\subsection{Dynamic potentiometry}

\subsubsection{Zero-current potentiometry}

For a traditional ion selective electrode, the ISE membrane is usually conditioned with the primary ion and the potential measurements are carried out under classical equilibrium conditions for the Nernstian response. In recent years, a number of new nonclassical potentiometric concepts based on non-equilibrium

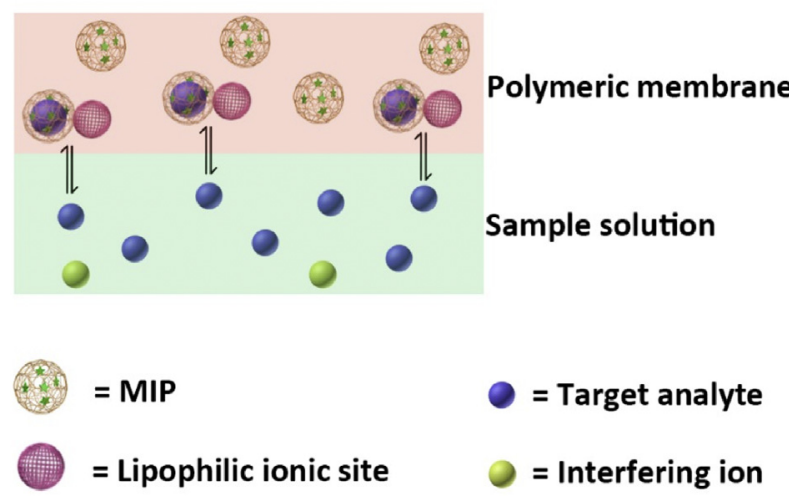

Fig. 5. A schematic view of the equilibrium between sample and ISE membrane containing a MIP receptor for classical potentiometry. In this classical mode, the ISE membrane is usually conditioned with the primary ion and the potential measurements are carried out under classical equilibrium conditions for the Nernstian response. mechanism have been proposed [49-51]. Unlike the traditional ones, before measurements, these electrodes are conditioned with the highly discriminated ions rather than the primary ions. The ISE responses to the primary ions in the aqueous solution are based on the non-equilibrium ion-exchange process between the discriminated ions in the membrane phase and the primary ions in the aqueous phase. Such non-equilibrium ion-exchange process results in a kinetic potential response [52,53]. The earliest example is the chloride-conditioned anion-exchanger-based membrane ISEs for determination of lipophilic anions such as perchlorate and periodate [54]. Such a super-Nernstian non-equilibrium mechanism was later successfully applied to sensitive detection of polyions such as heparin and protamine, for which a steady-state potential response was obtained when the flux of polyion from the sample solution equaled that in the ISE membrane [55].

Interestingly, the non-equilibrium steady-state sensing mode is also applicable for MIP-based potentiometric sensors. Similarly, the MIP-based electrode is conditioned in a solution of the interfering ions so that the ionic sites of the membrane are completely occupied by the interfering ions. When the membrane electrode contacts with the primary ions, the interfering ions in the membrane surface can be displaced by the primary ions due to the favorable host-guest interaction with the MIP in the membrane [28], thus resulting in a non-equilibrium steady-state potential response.

In order to further improve the detection sensitivity, an asymmetric polymeric membrane ISE configuration has been constructed [56]. In this method, the lipophilic ion-exchanger is evenly spread onto the surface of the polymeric membrane rather than being incorporated into the bulk of the membrane matrix as for the conventional ISEs. Therefore, the diffusion of the primary ions from the surface of the sensing membrane to the bulk of the membrane can be prevented. Since the detection sensitivity depends on the accumulation of the primary ions in the interfacial layer of the sensing membrane, a lower detection limit can be obtained [56]. By using the rotating electrode configuration, the diffusion layer thickness of the solution phase is effectively reduced, and the mass transfer of the primary ions to the sample-membrane interface is significantly increased [57], thus promoting the accumulation of the primary ions. By using the triclosan imprinted nanoparticles as the receptor prepared by precipitation polymerization [58], the proposed protocol was used to sensitively detect the triclosan ions (Fig. 6). The proposed electrode showed an excellent selectivity to triclosan over its analogs such as 4-phenoxyphenol, 4-methoxyphenol and catechol and some inorganic anions (e.g., $\mathrm{HCO}_{3}^{-}$and $\mathrm{CO}_{3}^{2-}$ ). The logarithmic Nikolskii coefficients for triclosan over 4-phenoxyphenol-, 4-methoxyphenol',

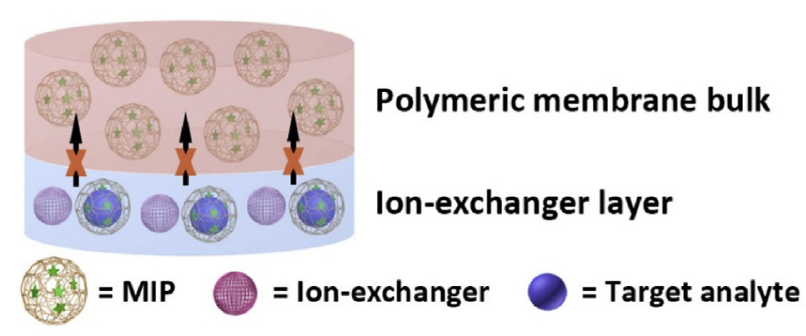

Fig. 6. Illustration of the MIP-based asymmetric ISE membrane. The asymmetric MIP membrane is formed by spreading the ion-exchanger solution onto the surface of the sensing membrane. The resultant membrane is conditioned in a solution of the interfering ions. When the electrode is in contact with the primary ions, the interfering ions in the membrane surface can be partially displaced by the primary ions due to the favorable host-guest interactions with the MIP receptor, thus causing a steady-state potential response. Since the primary ions can accumulate in the interfacial layer of the membrane rather than diffuse further into the membrane bulk, a lower detection limit can be achieved [58]. 
catechol ${ }^{-}$and $\mathrm{HCO}_{3}^{-}$were $-2.2,-4.3,-3.9$ and -9.7 , respectively. The ISE based on the MIP showed remarkably improved sensitivity for triclosan detection with a detection limit of $1.9 \times 10^{-9} \mathrm{~mol} / \mathrm{L}$. In addition, after each measurement, the ISE membrane became reuseable after regeneration by using a mixture of organic solvent and water.

\subsubsection{Chronopotentiometry}

Recent research has demonstrated that the applicability of the ISEs can be significantly expanded by combining them with other electrochemical (amperometry, coulometry, chronopotentiometry and ion-transfer voltammetry) or optical methodologies [59-63]. This may allow one to obtain additional analytical information and/ or to improve the system's robustness and performance characteristics, such as operational reversibility, sensitivity and selectivity. Chronopotentiometry remains a popular readout mode for conventional ISEs. The ISEs can be interrogated under galvanostatic control and used for the chronopotentiometric detection in analogy to zero-current potentiometry. Such technique usually applies a galvanostatic current pulse to control the ion fluxes from the sample solution into the sensing membrane, which producing a net ion flux at the membrane-solution phase interface. The pulsed galvanostatic-controlled ion-selective sensors offer several advantages, including the capability of multianalyte detection, reversible response to polyionic compounds, drastic improvement of sensitivity and selectivity [61,64-66]. The measurement principle is illustrated in Fig. 7 with a cation-selective ISE membrane as a model system [64]. In this system, a zero current measurement (pulse I) is first imposed. Then a controlled cathodic current (pulse II) of defined magnitude and duration is followed, which leads to a flux of sample cations in direction of the ion-selective membrane. All extracted ions are finally expelled from the membrane during a

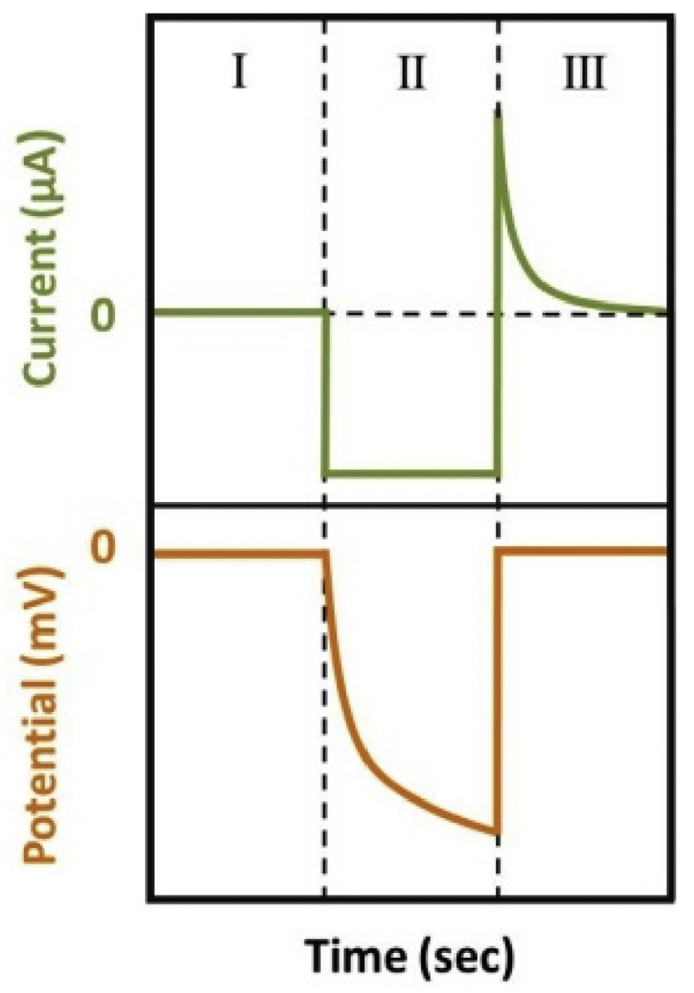

Fig. 7. Time profiles of the triple pulse experiment to control the ISE. Pulse I is a zerocurrent measurement pulse; pulse II applies a cathodic current to generate a defined ion flux in the direction of the membrane; pulse III is a potential controlled baseline pulse for regeneration of the membrane [64]. baseline potential (pulse III) by which the sensing membrane can finally be regenerated.

Chronopotentiometric sensors based on the MIPs that act as recognition elements in the polymeric membrane can achieve sensitive, reversible and rapid detection of the target molecules. Qin et al. applied this electrochemical protocol combined with a surface imprinting technique to detect biological species [13]. The sensing method was based on the blocking mechanism by which the recognition reaction between the surface-imprinted polymer and the bioanalyte could block the current-induced ion transfer of an indicator ion, thus inducing a potential change [67]. The present method offered high sensitivity and excellent selectivity for detection of biological species. As models, trypsin and yeast cells could be measured at levels down to $0.03 \mathrm{U} / \mathrm{mL}$ and $50 \mathrm{CFU} / \mathrm{mL}$, respectively [13].

\section{MIP-based potentiometric sensors}

Unlike the classical ionophore-based ISEs which are routinely designed for detection of inorganic ions (e.g., electrolyte ions and heavy metal ions), MIP-based potentiometric sensors are mainly used for determination of organic or biological species. During the past 30 years, various potentiometric sensors using the MIPs as the receptors have been developed and applied to quantify clinically and environmentally relevant organic ions (e.g., pharmaceuticals and pesticides), undissociated neutral phenols, organic neutral molecules (organic pollutants) and biological species (e.g., proteins and cells). Additionally, inorganic ions (e.g., heavy metal ions and electrolyte ions) can also be used as the targets of MIP-based potentiometric sensors although the selectivities towards inorganic ions are not satisfactory.

\subsection{Organic species}

\subsubsection{Organic ions and undissociated neutral phenols}

Currently, potentiometric sensors based on the MIP receptors have been successfully developed for determination of organic ions such as toxic additive (e.g., protonated melamine and undissociated bisphenol analogs) $[12,26,27]$. Since non-covalent imprinting is easier to achieve and applicable to a wider spectrum of templates, this method has become the most popular and general strategy for the synthesis of the organic ion, and neutral phenol-imprinted receptors of MIP-based potentiometric sensors [18]. In the recognition process, various non-covalent interactions are formed including hydrogen bonds, ionic interactions, van der Waals forces and $\pi-\pi$ interactions between the organic templates and the functional monomers [19]. Due to the intrinsic properties of noncovalent recognition which has a fast binding and release of the guest, potentiometric sensors towards these organic species usually have a short response time.

For potentiometric detection of an organic ion, a buffer which can make sure that the organic target occurs mainly or almost exclusively in its ionic form is usually required. After protonation or deprotonation, the obtained organic ions can thus be measured potentiometrically by the ISE. Melamine, a common toxic compound, is a weak base with a $\mathrm{pK}_{\mathrm{a}}$ of 5.05 , and is readily protonated in aqueous solution at $\mathrm{pH}$ lower than 5.0. The protonated melamine can be detected by MIP-based potentiometric sensor as described by Qin and coworkers [12]. The preparation process of the melamine-imprinted polymer is shown in Fig. 8. The interactions between the functional monomer methacrylic acid and melamine are mainly hydrogen bondings. The membrane electrode showed a near-Nernstian response to protonated melamine over the concentration range of $5.0 \times 10^{-6}$ to $1.0 \times 10^{-2} \mathrm{~mol} / \mathrm{L}$, and the response of the sensor was rapid ( 16 s). The MIP-based ISE 


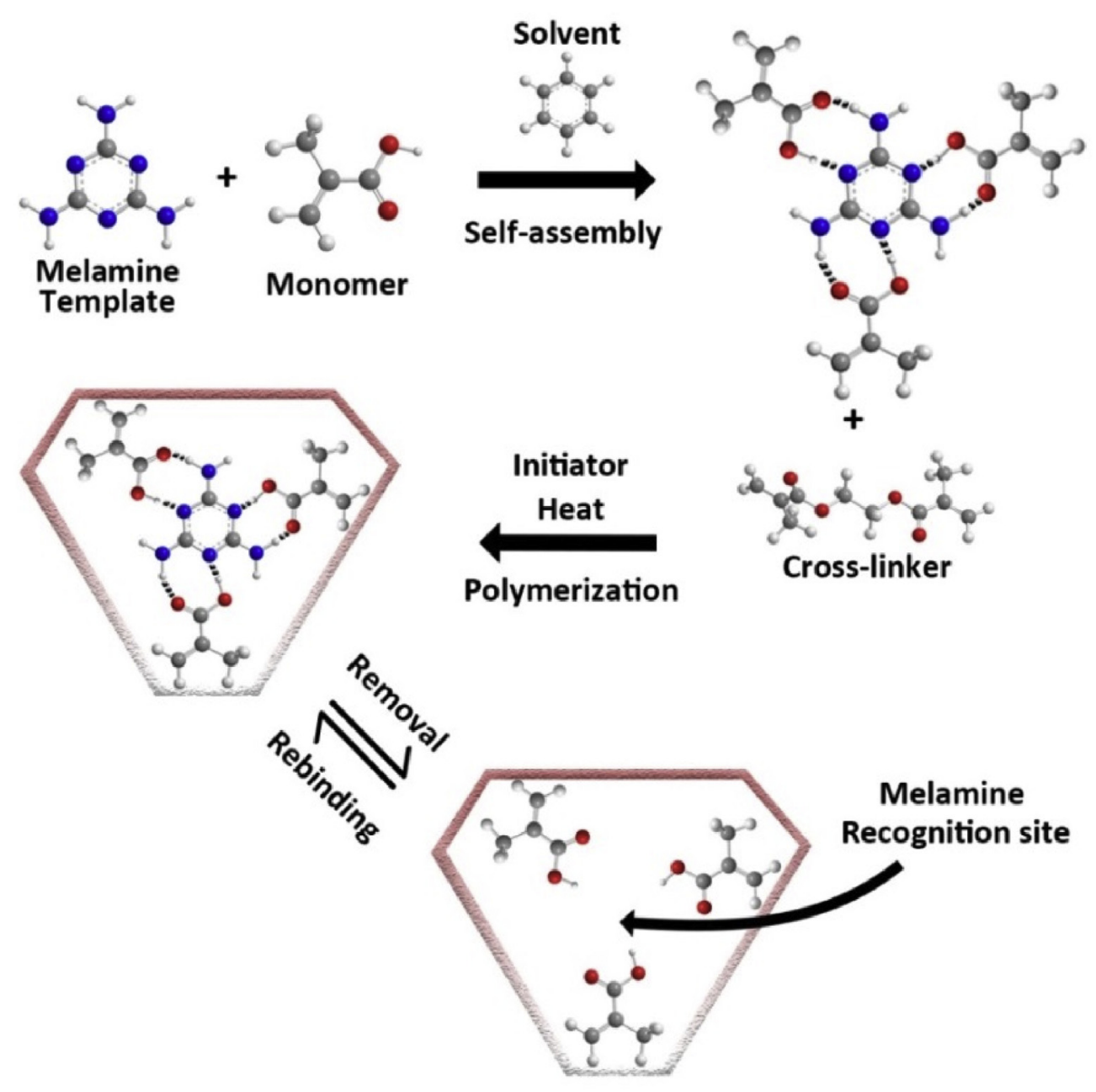

Fig. 8. Schematic representation of the preparation of the melamine-imprinted polymers [12].

showed a relatively good selectivity over other inorganic cations such as $\mathrm{Na}^{+}, \mathrm{K}^{+}, \mathrm{H}^{+}$and $\mathrm{Ca}^{2+}$, and the corresponding logarithmic selectivity coefficients were $-4.65,-3.96,-4.95$ and -9.3 , respectively.

Pharmaceuticals, including veterinary and human antibiotics, antihypertension agents and other drugs, have gained increasing attention due to their continuous release to the environment. Therefore, reliable analytical methods are required for monitoring these pharmaceuticals in the environment. Sales et al. [68] prepared the ciprofloxacin-imprinted polymers by co-polymerizing methacrylic acid or 2-vinyl pyridine functional monomers in the presence of ciprofloxacin as the template molecule. The obtained potentiometric sensor based on the ciprofloxacin-imprinted receptor exhibited high sensitivity, good stability and excellent selectivity with a detection limit of $1.0 \times 10^{-5} \mathrm{~mol} / \mathrm{L}$ for the ciprofloxacin ions. The same group also used MIP-based potentiometric sensors to detect oxytetracycline [69] and chlorpromazine ions [70] in real samples. The detection limits for the former and the latter were $19.8 \mu \mathrm{g} / \mathrm{mL}$ and $0.46 \mu \mathrm{g} / \mathrm{mL}$, respectively. Barrio's group reported chiral imprinted nanoparticles synthesized by precipitation polymerization using the $\mathrm{S}$ enantiomer of citalopram as the template. They used these nanoreceptors as the sensing element to fabricate potentiometric sensor [71]. The obtained sensor exhibited excellent enantioselectivity and had a Nernstian response to the protonated citalopram over the concentration range of $2.5 \times 10^{-7}$ to $1.0 \times 10^{-3} \mathrm{~mol} / \mathrm{L}$. Shirzadmehr et al. [72] introduced a MIP-based potentiometric sensor for selective determination of losartan ions. This sensor exhibited a Nernstian response in a wide linear range of $3.0 \times 10^{-9}$ to $1.0 \times 10^{-2} \mathrm{~mol} / \mathrm{L}$ with a lower detection limit of $1.82 \times 10^{-9} \mathrm{~mol} / \mathrm{L}$, a fast response time of ca. $6 \mathrm{~s}$ and a high selectivity over other interfering compounds.

Pesticide residues may be found in water, soils, fruits and vegetables and can give rise to serious risks to the health and the safety of the consumers. Thus, evaluation and detection of trace-level pesticide residues are necessary for environmental pollution control and human health. El Azab et al. [73] described a potentiometric sensor based on the MIPs for determination of the dinotefuran ions in cucumber and the soil samples with a detection limit of $0.35 \mu \mathrm{g} / \mathrm{L}$. Agostino et al. [74] developed a potentiometric sensor for determination of the atrazine ions by using the MIP as the sensing element. The detection limit for the atrazine ions was around $2.0 \times 10^{-5} \mathrm{~mol} / \mathrm{L}$.

Besides organic ions, undissociated neutral phenols can also be detected by potentiometric sensors based on the MIPs. Although it has been revealed that undissociated neutral phenols and their derivatives could generate strong anionic potential responses on quaternary ammonium salt-doped polymeric membrane ISEs under near-neutral pH conditions [75], the selectivity of such sensors is rather poor since the response is mainly governed by the acidity and lipophilicity of each phenolic compound rather than specific molecular recognition. Hence, Qin et al. developed a series of potentiometric sensors with the MIPs for sensitive and selective detection of bisphenols including bisphenol A (BPA) [76], bisphenol S (BPS) [27] 
and bisphenol AF (BPAF) [20] based on the nonequilibrium response mechanism. In order to guarantee that these phenols exist mostly in their neutral forms, the buffers with $\mathrm{pHs}$ lower than their $\mathrm{pK}_{\mathrm{a}}$ values were used as the background solutions. By incorporation of the MIP in the sensing membrane, the selectivity and sensitivity of the electrode can be largely improved due to the high affinity between the MIP and the phenols. All these sensors exhibited excellent selectivities towards the target phenol over other phenols even the interfering phenol had a structure similar to the target phenol. In addition, the detection limits of the ionophore-free electrodes for neutral phenols were higher than micromolar level, while those of the electrodes based on the MIPs were in the nanomolar concentration range (e.g., BPA, $20 \mathrm{nM}$; BPS, $40 \mathrm{nM}$; BPAF, $60 \mathrm{nM}$ ).

\subsubsection{Neutral molecules}

It should be noted that the development of potentiometric sensor for detecting electrically neutral species remains a challenge since the primary condition for potential response is the occurrence of the charge of the analyte. To address this challenge, Qin et al. developed a strategy for selective and sensitive detection of neutral organic species (chlorpyrifos) using a polymeric membrane ISE based on the nonequilibrium response mechanism [24]. It was based on the uniform-sized MIP beads as the molecular recognition receptors for molecular recognition and a charged compound with a structure similar to that of the analyte as an indicator ion for the transduction of the potential signal (Fig. 9).

Before measurement, the membrane electrode was immersed in the sample solution containing chlorpyrifos. Due to the specific recognition interactions between chlorpyrifos and the MIPs on the surface of the sensing membrane, chlorpyrifos could be extracted into the surface of the membrane electrode. During the measurement, the indicator ions (3,5,6-trichloro-2-pyridyloxyacetic acid, the analogue of chlorpyrifos) could diffuse from the solution into the surface of the sensing membrane and interact with the recognition sites in the membrane phase. Since the binding sites were partially occupied by the chlorpyrifos molecules, the available binding sites for the indicator ions was greatly reduced after chlorpyrifos incubation, thus decreasing the potential response to the indicators ions. On the basis of a similar principle, Qin's group also proposed a MIP-based potentiometric sensor for determination of neutral toluene vapor [77]. The MIPs acted as receptors for selective adsorption of toluene vapor from the gas phase into the membrane phase. Benzoic acid was used as the indicator ions to indicate the potential changes induced by the toluene incubation. A detection limit of parts per million levels for toluene vapor could be obtained.

\subsection{Biological species}

While potentiometric detection of small organic molecules is now well established, the detection of biomacromolecules such as peptides, proteins and cells is still a challenge to implement, in part because (i) the synthesis of the MIP receptors with specific and selective imprinted cavities is extremely difficult due to the complexity of functional sites present in these biomacromolecular targets; (ii) these biological targets cannot induce the measureable potential signals when they transfer from the aqueous sample into the hydrophobic sensing membrane (polyions are exceptions). The group of Shea developed methods for synthesizing protein-sized polymer particles with a binding affinity and selectivity comparable to those of natural antibodies by combining MIP nanoparticle synthesis with a functional monomer optimization strategy [78]. Such strategy involves screening small libraries of nanoparticles that span a compositional space chosen for its complementarity to the biological target. In addition, a solid-phase synthesis approach to prepare MIP nanoparticles specific for the protein was described, in which an affinity ligand of the protein was attached to the solid support [79]. The resulting MIP exhibited high specificity and selectivity for the target. These attractive approaches have made great contributions towards biomacromolecule imprinting and will further facilitate detection of biological species using MIP-based potentiometric sensors.

Qin and coworkers developed a simple, efficient and label-free strategy for detecting biological species by using MIP-based potentiometric sensor based on the combination of chronopotentiometry and surface imprinting [13]. Fig. 10 illustrates the sensing mechanism of the proposed protocol. The proposed potentiometric sensor consisted of two layers: the imprinting recognition layer for the

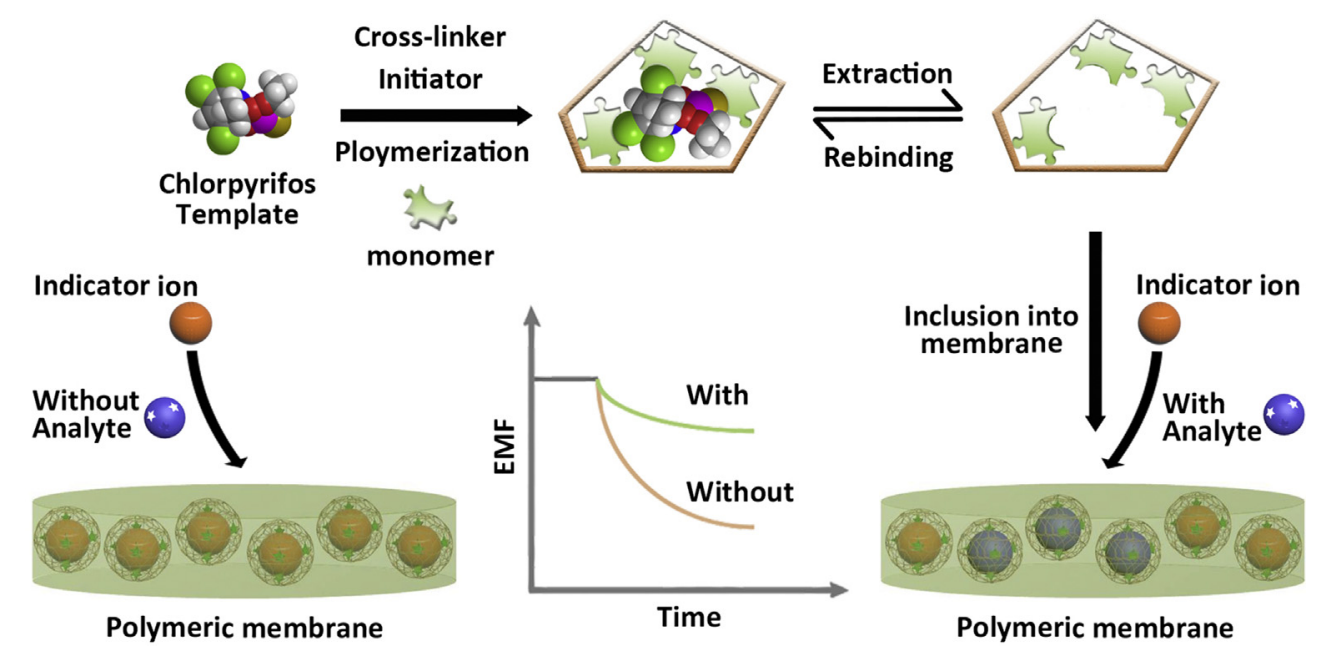

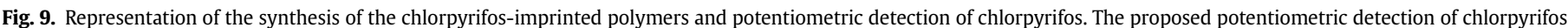

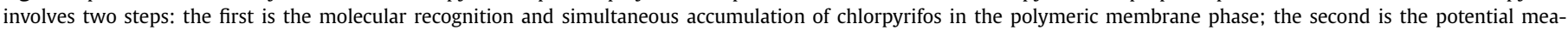

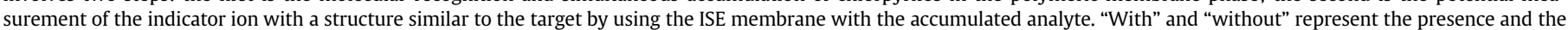
absence of the target (chlorpyrifos) in the sample solution, respectively [24]. 


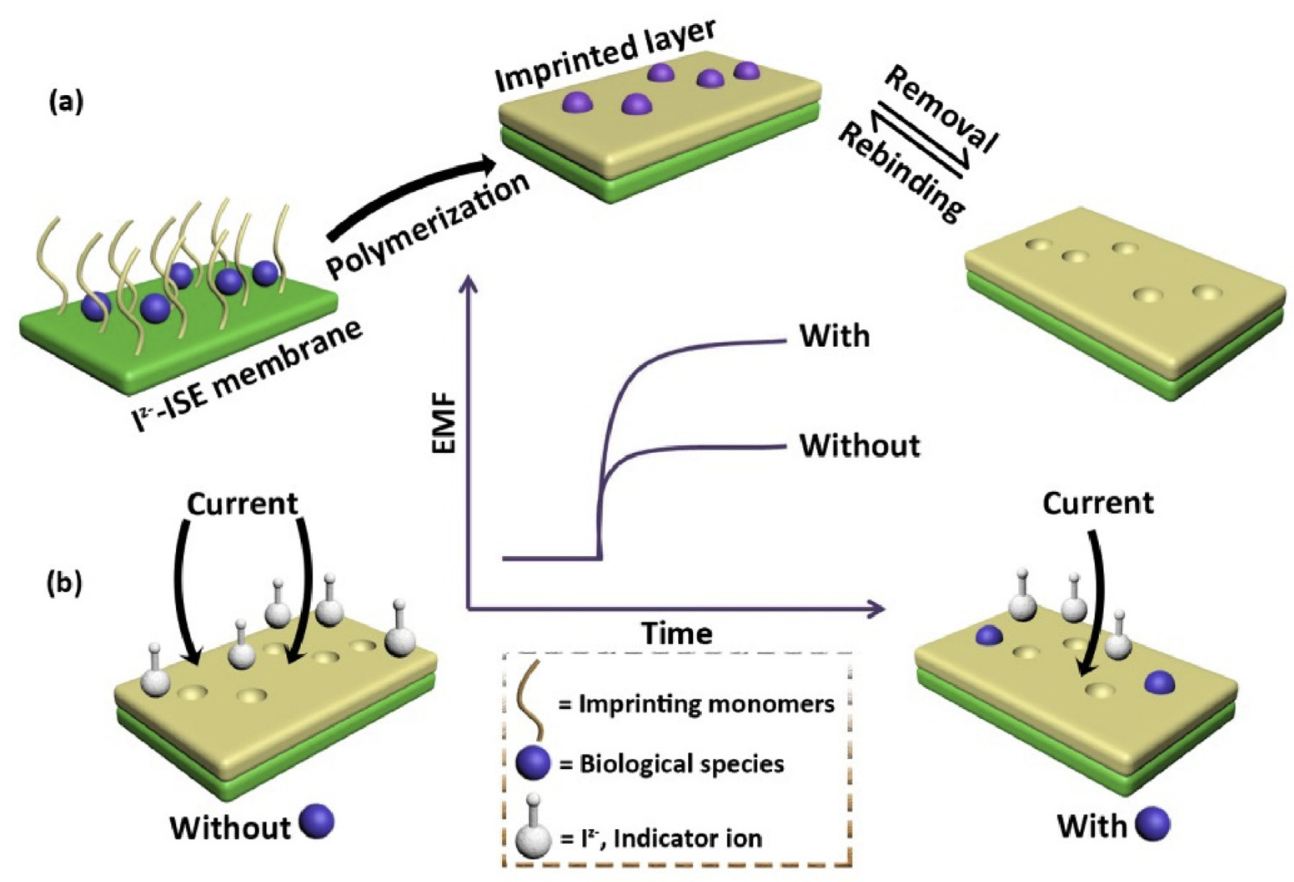

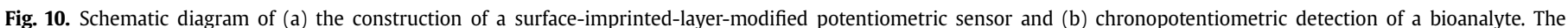

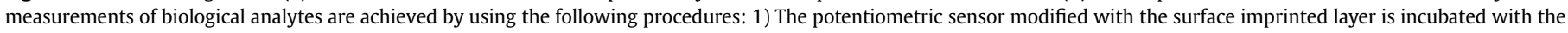

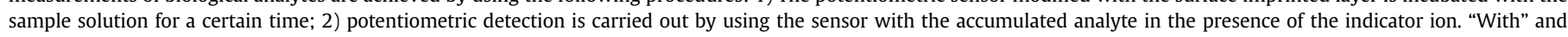
"without" represents the presence and the absence of biological analytes in the detection solution, respectively [13].

bioanalyte and the potentiometric transduction layer for the indicator ion. The recognition layer of the target analyte was prepared by surface imprinting on the surface of the potentiometric transduction layer. When the membrane electrode contacted with the sample solution, the selective recognition in the recognition layer would block the ion transfer of the indicator ion through the recognition layer into the transduction layer, which resulted in a potential change. The proposed sensor exhibited high sensitivity and excellent selectivity for detection of biological species with the detection limits of $0.03 \mathrm{U} / \mathrm{mL}$ and $50 \mathrm{CFU} / \mathrm{mL}$ for trypsin and yeast cells, respectively. However, it should be noted that it is still a big challenge to carry out specific and direct potentiometric sensing of bioanalytes. In this case, very few papers have been involved with potentiometric sensing of bioanalytes based on the MIP.

\subsection{Inorganic ions}

For potentiometric detection of inorganic ions such as the electrolyte ions and the heavy metal ions, the researchers normally use the classical ionophore-based polymeric membrane ISEs since the commercial available ionophores exhibit excellent recognition abilities towards the target inorganic ions. However, in recent years, many researchers have tried to explore the feasibility of using potentiometric sensors based on the ion imprinted polymers (IIPs) [80] as the carriers for determination of the inorganic ions although the selectivities of these sensors towards the inorganic ions are not satisfactory.

The pioneering work on the IIP-based ISEs for detection of heavy metal ions is reported by Murray et al. [81]. By using $\mathrm{Pb}^{2+}$ as a model and vinylbenzoic acid as the functional monomer, the proposed potentiometric sensor exhibited a near-Nernstian response in a wide linear concentration range. Although this work demonstrated that the electrode showed a strong preference for the templated metal ion over the other metal ions tested, the selectivity of this sensor was much worse than those of the classical $\mathrm{Pb}^{2+}$ ionophore (e.g., lead ionophore IV)-based potentiometric sensors. Qin's group also reported a $\mathrm{Cu}^{2+}$ IIP-based potentiometric sensor [82]. The IIP was synthesized by precipitation polymerization using methacrylic acid as the functional monomer. Similarly, the selectivity of the obtained sensor toward singly charged cations such as $\mathrm{Na}^{+}$and $\mathrm{K}^{+}$was still not satisfactory. The poor selectivities of both sensors can be probably ascribed to the fact that heavy metal ions, unlike organic and biological species, have so small sizes that they cannot be imprinted effectively. In addition, the common functional monomers (e.g., vinylbenzoic acid and methacrylic acid) cannot form strong coordination interactions with heavy metal ions.

To overcome these drawbacks and make ion imprinting more efficient, the selective ligands which can coordinate selectively with heavy metal ions were employed in the preparation of the IIPs. Shirzadmehret et al. synthesized the $\mathrm{Ag}^{+}$and $\mathrm{Hg}^{2+}$ IIPs using an aza-thioether crown containing a 1,10-phenanthroline subunit and 4-(2-thiazolylazo) resorcinol as the recognition ligands, respectively [83,84]. These IIPs were used as the sensing element of potentiometric sensors. The obtained sensors exhibited improved selectivities compared to the other IIP-based potentiometric sensors. Unfortunately, these selective ligands were not copolymerized into the IIP matrix in the synthesis, which may affect the stabilities of the complexes between heavy metal ions and the IIPs.

The interesting strategy for the fabrication of highly selective IIP-based potentiometric sensors was described by Mosbach and Simon [85]. The proposed procedures for synthesis of the IIP are shown in Fig. 11. It was based on the combination of the ion imprinting recognition with a selective coordination interaction. A polymerisable $\mathrm{Ca}^{2+}$ ionophore (ETH 129) was used as the functional monomer. This would provide the size-exclusion selectivity coupled with the selectivity for the target ions to coordinate favorably with the ion-imprinting polymer within the membrane. The imprinting process enabled enhanced selectivity for $\mathrm{Ca}^{2+}$ by a factor of 6 . However, the data about the proposed potentiometric sensor with the ionophore-based IIP as the receptor was not 

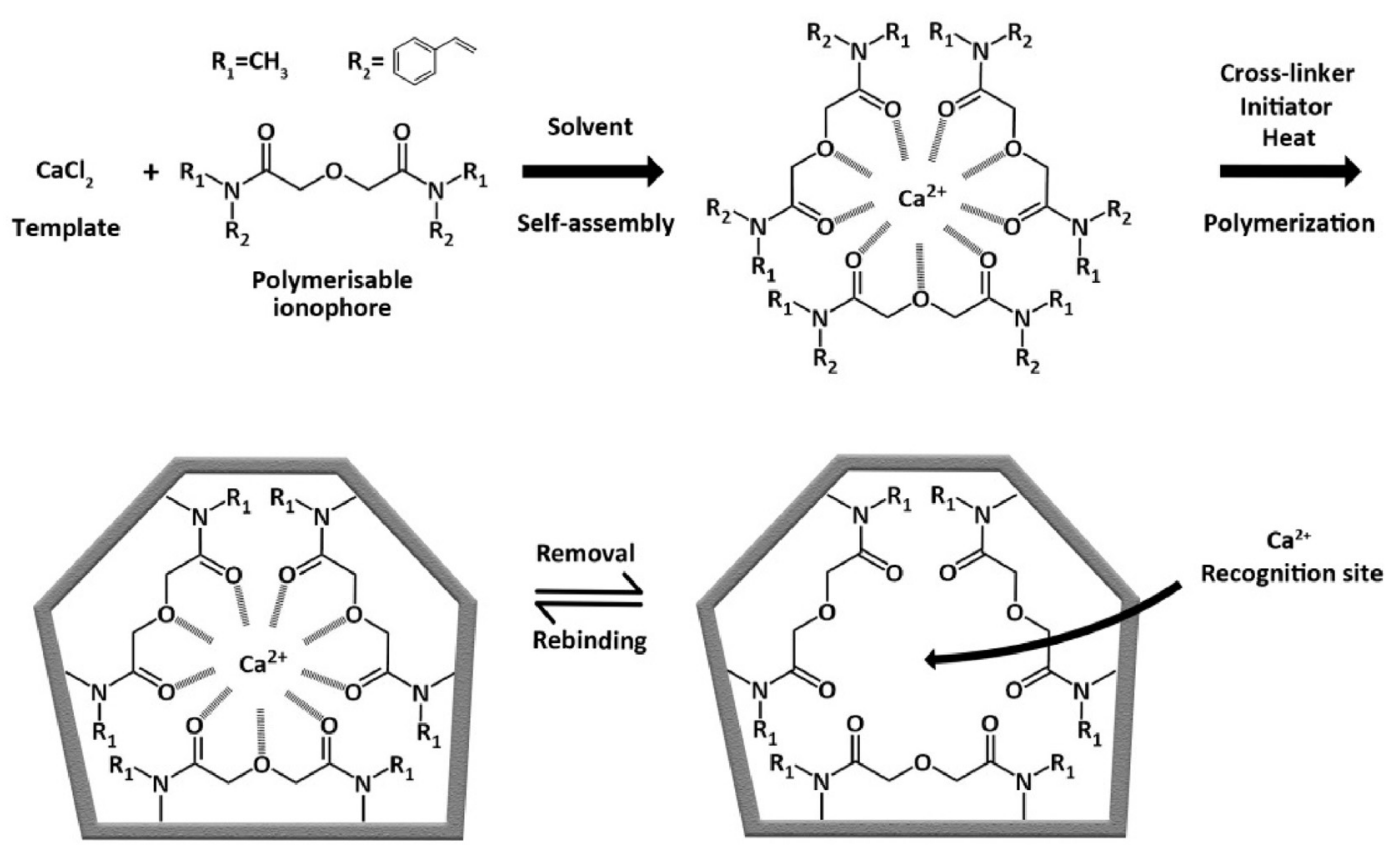

Fig. 11. Illustration of the preparation of the $\mathrm{Ca}^{2+}$-imprinted polymers base on the polymerisable $\mathrm{Ca}^{2+}$ ionophore as the functional monomer [85].

provided, which is probably owing to the unsatisfactory result. Note that, although this work was proposed as early as 1991, such strategy is still an interesting approach for improvement of the selectivity of IIP-based potentiometric sensors. In addition, in recent years, using a mixture of the classical functional monomers [86] and utilizing a specific recognition molecular as the functional monomer $[87,88]$ may shed new lights on the IIP. These approaches may be effective for the improvement of the IIP selectivity. Note that, till now, many IIP-based potentiometric sensors have been developed, but most of them show unsatisfactory selectivities towards the template over other inorganic ions as compared to those based on ionophores.

\section{Conclusions}

MIP-based potentiometric sensors are a promising and useful technology for detection of environmental contaminants, hazardous substances and bioanalytes due to their low cost, ease of operation, excellent selectivity and high stability. The past few decades have witnessed remarkable achievements in MIP-based potentiometric sensors. These major achievements have facilitated new applications for which potentiometric sensors have not been used traditionally. The development of such sensors may open new attractive horizons for potentiometric sensing and further expand the field.

\section{Outlook}

At present, there are several interesting research developments that may have an impact on the future developments of MIP-based potentiometric sensors.

Stimuli-responsive polymers, known as smart polymers, are able to respond to specific external stimuli by changing their properties such as molecular structures, surface characteristics and dissolution behaviors $[89,90]$. By combining the molecular imprinting technique with the stimuli-responsive materials, the stimuli-responsive MIPs have been developed, which possess both the stimuli-responsive properties and molecular recognition abilities [91]. In contrast to the traditional MIPs, the recognition abilities of the stimuliresponsive MIPs can be controlled by external stimuli, such as changes in $\mathrm{pH}$, light or temperature. The recognition of the template can be specific when the MIP maintains a 3D structure similar to the imprinting state, whereas the memory of the template will be lost when an external stimulus breaks the imprinting state [92,93]. When these receptors are incorporated into the sensing membrane of polymeric membrane potentiometric sensors, the obtained sensors will become much smarter [26].

Other emerging field is the fabrication of low-cost sensors. Expensive electrode substrates such as gold, platinum and glassy carbon usually restrict the wide application of the MIP-based ISEs, especially in the less developed countries. As an inexpensive and flexible material, paper has become a very attractive substrate for constructing potentiometric sensors. Liang et al. proposed the MIPbased potentiometric paper sensor. Uniform-sized MIP nanobeads were synthesized and incorporated into the sensing membrane for selective recognition of the target analyte. The proposed potentiometric sensor could be effectively employed as the sensing platform for sensitive detection of BPA [94]. Paper-based devices are promising to fabricate cheap and portable sensors for potentiometric detection of organic compounds.

Wearable sensors have received considerable attention due to their great promise for a wide range of clinical and physiological applications $[95,96]$. Thus, such area may be another trend of MIPbased potentiometric sensors. A wearable potentiometric sensor is a relatively new concept that borrows fundamental from the ISE field among the integration of new materials and electronics into a configuration that enables on-body measurements [97,98]. At present, such technology is a hot topic for ion detection in healthcare and sport performance monitoring. Since many MIP receptors have been extensively exploited in analytical chemistry, it can be expected that this technology provides considerable promise to develop MIP-based wearable potentiometric sensors for on-body sensing of organic and biological species related with human health.

This review summarizes recent advances in preparation method and the applications of potentiometric sensors based on the MIPs 
Table 1

Comparison of different preparation methods for the MIPs.

\begin{tabular}{|c|c|c|c|c|c|c|c|c|c|}
\hline Synthesis technique & Advantage & Disadvantage & Template & Monomer/cross-linker & Size & Template extraction & Linear range & Limit of detection & Ref. \\
\hline \multirow[t]{2}{*}{ Bulk polymerization } & \multirow{2}{*}{$\begin{array}{l}\text { Fast and simple } \\
\text { synthesis; high MIP } \\
\text { purity }\end{array}$} & \multirow{2}{*}{$\begin{array}{l}\text { Tedious crushed, } \\
\text { ground and sieved } \\
\text { processes; irregular } \\
\text { particles in shape and } \\
\text { size; heterogeneous } \\
\text { binding site } \\
\text { distribution }\end{array}$} & Moxifloxacin & $\mathrm{MAA}^{\mathrm{a}}$ or $4-\mathrm{VP}^{\mathrm{b}} / \mathrm{EGDMA}^{\mathrm{c}}$ & $<100 \mu \mathrm{m}$ & $\begin{array}{l}\text { Water/acetic acid (9/1, } \\
\mathrm{v} / \mathrm{v})\end{array}$ & $1.0 \times 10^{-5}-1.0 \times 10^{-2} \mathrm{~mol} / \mathrm{L}$ & $1.7 \times 10^{-6} \mathrm{~mol} / \mathrm{L}$ & [23] \\
\hline & & & Chlorpromazine & AAMPSO $^{\mathrm{d}} / \mathrm{EGDMA}$ & $50-150 \mu \mathrm{m}$ & $\begin{array}{l}\text { Methanol/acetic acid } \\
(5 / 1, v / v)\end{array}$ & $4.1 \times 10^{-6}-1.6 \times 10^{-3} \mathrm{~mol} / \mathrm{L}$ & $1.3 \times 10^{-6} \mathrm{~mol} / \mathrm{L}$ & [70] \\
\hline \multirow[t]{3}{*}{$\begin{array}{l}\text { Precipitation } \\
\text { polymerization }\end{array}$} & \multirow{3}{*}{$\begin{array}{l}\text { High quality and uni- } \\
\text { form particle size; } \\
\text { simple synthesis }\end{array}$} & \multirow{3}{*}{$\begin{array}{l}\text { Large amount of } \\
\text { porogenic solvent; long } \\
\text { polymerization time }\end{array}$} & 2-naphthoic acid & $\mathrm{AM}^{\mathrm{e}}, \mathrm{MMA}^{\mathrm{f}} / \mathrm{TRIM}^{\mathrm{g}}, \mathrm{DVB}^{\mathrm{h}}$ & $200-300 \mathrm{~nm}$ & $\begin{array}{l}\text { Methanol/acetic acid } \\
(8 / 2, v / v)\end{array}$ & $1.0 \times 10^{-10}-5.0 \times 10^{-9} \mathrm{~mol} / \mathrm{L}$ & $6.9 \times 10^{-11} \mathrm{~mol} / \mathrm{L}$ & [28] \\
\hline & & & Triclosan & AM, MMA/TRIM, DVB & $200-300 \mathrm{~nm}$ & $\begin{array}{l}\text { Methanol/acetic acid } \\
(8 / 2, v / v)\end{array}$ & $1.0 \times 10^{-8}-1.0 \times 10^{-6} \mathrm{~mol} / \mathrm{L}$ & $1.9 \times 10^{-9} \mathrm{~mol} / \mathrm{L}$ & [58] \\
\hline & & & Citalopram & Itaconic acid/EGDMA & $<1 \mu \mathrm{m}$ & $\mathrm{ACN}^{\mathrm{i}}$ & $2.5 \times 10^{-7}-1.0 \times 10^{-3} \mathrm{~mol} / \mathrm{L}$ & $1.25 \times 10^{-7} \mathrm{~mol} / \mathrm{L}$ & [71] \\
\hline $\begin{array}{l}\text { Surface imprinting } \\
\text { (solid-phase } \\
\text { imprinting) }\end{array}$ & $\begin{array}{l}\text { High binding capacity; } \\
\text { accessible binding sites; } \\
\text { suitable for } \\
\text { macromole- cules } \\
\text { imprinting; fast } \\
\text { association/dissociation } \\
\text { kinetics }\end{array}$ & $\begin{array}{l}\text { Limited surface area of } \\
\text { the substrate; low } \\
\text { amount of the resultant } \\
\text { imprinting cavities }\end{array}$ & $\begin{array}{l}\text { Histamine } \\
\text { Cocaine }\end{array}$ & $\begin{array}{l}\text { MAA/EGDMA } \\
\text { AM/EGDMA }\end{array}$ & $\begin{array}{l}<0.45 \mu \mathrm{m} \\
90-130 \mathrm{~nm}\end{array}$ & $\begin{array}{l}\text { ACN } \\
\text { Water or ACN }\end{array}$ & $\begin{array}{l}1.0 \times 10^{-6}-1.0 \times 10^{-2} \mathrm{~mol} / \mathrm{L} \\
1.0 \times 10^{-9}-1.0 \times 10^{-3} \mathrm{~mol} / \mathrm{L}\end{array}$ & $\begin{array}{l}1.12 \times 10^{-6} \mathrm{~mol} / \mathrm{L} \\
<1 \mathrm{nmol} / \mathrm{L}\end{array}$ & $\begin{array}{l}{[34]} \\
{[37]}\end{array}$ \\
\hline Electro-polymerization & $\begin{array}{l}\text { Fast synthesis; } \\
\text { Possibility of } \\
\text { imprinting in water; } \\
\text { controlled polymer film } \\
\text { thickness; superior } \\
\text { adherence to the } \\
\text { electrode surface }\end{array}$ & $\begin{array}{l}\text { Low template removal } \\
\text { efficiency; limited } \\
\text { number of electroactive } \\
\text { monomers }\end{array}$ & $\begin{array}{l}\mathrm{NO}_{3}^{-} \\
\text {L-ascorbic acid }\end{array}$ & $\begin{array}{l}\text { N-methylpyrrole/- } \\
\text { Pyrrole/- }\end{array}$ & $\begin{array}{l}- \\
1.6-1.8 \mu \mathrm{m} \\
\text { (thickness) }\end{array}$ & $\begin{array}{l}\text { Applied voltage } \\
\text { Applied voltage }\end{array}$ & $\begin{array}{l}5.0 \times 10^{-6}-1.0 \times 10^{-4} \mathrm{~mol} / \mathrm{L} \\
5.0 \times 10^{-6}-2.0 \times 10^{-3} \mathrm{~mol} / \mathrm{L}\end{array}$ & $\begin{array}{l}<5 \mu \mathrm{mol} / \mathrm{L} \\
<5 \mu \mathrm{mol} / \mathrm{L}\end{array}$ & $\begin{array}{l}{[43]} \\
{[44]}\end{array}$ \\
\hline
\end{tabular}

a MAA, Methacrylicacid.
b 4-VP, 4-vinylpyridine.

c EGDMA, Ethylene glycol dimethacrylate.

d AAMPSO, 2-acrylamido-2-methyl-1-propanesulfonic acid.

e Am, Acrylamide.

${ }^{f}$ MMA, Methyl methacrylate.

g TRIM, Trimethylolpropanetrimethacrylate.

h DVB, Divinylbenzene.

${ }^{\mathrm{i}} \mathrm{ACN}$, Acetonitrile. 
Table 2

Applications of potentiometric sensors based on MIPs.

\begin{tabular}{|c|c|c|c|c|c|c|c|}
\hline & $\begin{array}{l}\text { Target analyte } \\
\text { (Template) }\end{array}$ & Monomer/cross-linker & Preparation method & Detection mode & Linear range & Limit of detection & Ref. \\
\hline \multirow[t]{4}{*}{ Organic ions } & Melamine & MAA $^{\mathrm{a}} / \mathrm{EGDMA}^{\mathrm{b}}$ & Bulk polymerization & Classical potentiometry & $5.0 \times 10^{-6}-1.0 \times 10^{-2} \mathrm{~mol} / \mathrm{L}$ & $6.0 \times 10^{-6} \mathrm{~mol} / \mathrm{L}$ & [12] \\
\hline & Ciprofloxacin & MAA/EGDMA & Bulk polymerization & Classical potentiometry & $2.0 \times 10^{-5}-1.8 \times 10^{-3} \mathrm{~mol} / \mathrm{L}$ & $1.0 \times 10^{-5} \mathrm{~mol} / \mathrm{L}$ & [68] \\
\hline & Oxytetracycline & MAA/EGDMA & Bulk polymerization & Classical potentiometry & $5.0 \times 10^{-5}-1.0 \times 10^{-2} \mathrm{~mol} / \mathrm{L}$ & $19.8 \mu \mathrm{g} / \mathrm{mL}$ & [69] \\
\hline & Dinotefuran & $\mathrm{AM}^{\mathrm{C}} / \mathrm{EGDMA}$ & Bulk polymerization & Classical potentiometry & $1.0 \times 10^{-7}-1.0 \times 10^{-2} \mathrm{~mol} / \mathrm{L}$ & $0.35 \mu \mathrm{g} / \mathrm{L}$ & [73] \\
\hline \multirow{2}{*}{$\begin{array}{l}\text { Undissociated } \\
\text { neutral } \\
\text { phenols }\end{array}$} & Bisphenol A & 4-VP/EGDMA & $\begin{array}{l}\text { Semi-covalent imprinting } \\
\text { technique }\end{array}$ & $\begin{array}{l}\text { Dynamic potentiometry } \\
\text { (non-equilibrium mechanism) }\end{array}$ & $1.0 \times 10^{-7}-1.0 \times 10^{-6} \mathrm{~mol} / \mathrm{L}$ & $2.0 \times 10^{-8} \mathrm{~mol} / \mathrm{L}$ & {$[76]$} \\
\hline & Bisphenol AF & MAA/DVB $80^{e}$ & $\begin{array}{l}\text { Precipitation } \\
\text { polymerization } \\
\text { and high-temperature } \\
\text { swelling }\end{array}$ & $\begin{array}{l}\text { Dynamic potentiometry } \\
\text { (non-equilibrium mechanism) }\end{array}$ & $1.0 \times 10^{-7}-1.0 \times 10^{-6} \mathrm{~mol} / \mathrm{L}$ & $6.0 \times 10^{-8} \mathrm{~mol} / \mathrm{L}$ & {$[20]$} \\
\hline \multirow[t]{2}{*}{$\begin{array}{l}\text { Neutral } \\
\text { molecules }\end{array}$} & Chlorpyrifos & $\begin{array}{l}\text { MAA/TRIM } \\
\text { and } \text { DVB }^{\mathrm{g}}\end{array}$ & $\begin{array}{l}\text { Precipitation } \\
\text { polymerization }\end{array}$ & $\begin{array}{l}\text { Dynamic potentiometry } \\
\text { (non-equilibrium mechanism) }\end{array}$ & $2.0 \times 10^{-9}-5.0 \times 10^{-8} \mathrm{~mol} / \mathrm{L}$ & $9.6 \times 10^{-10} \mathrm{~mol} / \mathrm{L}$ & {$[24]$} \\
\hline & Toluene & MAA/DVB 80 & $\begin{array}{l}\text { Precipitation } \\
\text { polymerization }\end{array}$ & $\begin{array}{l}\text { Dynamic potentiometry } \\
\text { (non-equilibrium mechanism) }\end{array}$ & $10-125 \mathrm{ppm}$ & $3.5 \mathrm{ppm}$ & [77] \\
\hline \multirow[t]{2}{*}{$\begin{array}{r}\text { Biological } \\
\text { species }\end{array}$} & Trypsin & $\mathrm{PDA}^{\mathrm{h}}$ & Surface imprinting & $\begin{array}{l}\text { Dynamic potentiometry } \\
\text { (Chronopotentiometry) }\end{array}$ & $0.08-4 \mathrm{U} / \mathrm{mL}$ & $0.03 \mathrm{U} / \mathrm{mL}$ & [13] \\
\hline & Yeast cells & PDA & Surface imprinting & $\begin{array}{l}\text { Dynamic potentiometry } \\
\text { (Chronopotentiometry) }\end{array}$ & $100-1500 \mathrm{CFU} / \mathrm{mL}$ & $50 \mathrm{CFU} / \mathrm{mL}$ & [13] \\
\hline \multirow[t]{2}{*}{$\begin{array}{l}\text { Inorganic } \\
\text { ions }\end{array}$} & Lead (II) ion & $\begin{array}{l}\text { Vinylbenzoic } \\
\text { acid/DVB }\end{array}$ & Bulk polymerization & Classical potentiometry & $1.0 \times 10^{-6}-5.0 \times 10^{-3} \mathrm{~mol} / \mathrm{L}$ & $<1.0 \mu \mathrm{mol} / \mathrm{L}$ & [81] \\
\hline & Silver (I) ion & $\begin{array}{l}\text { Aza-thioether } \\
\text { crown } \\
\text { and MAA/EGDMA }\end{array}$ & $\begin{array}{l}\text { Precipitation } \\
\text { polymerization }\end{array}$ & Classical potentiometry & $3.2 \times 10^{-9}-1.0 \times 10^{-1} \mathrm{~mol} / \mathrm{L}$ & $1.2 \times 10^{-9} \mathrm{~mol} / \mathrm{L}$ & [83] \\
\hline $\begin{array}{ll}\text { a } & \text { MAA, Methac } \\
\text { b } & \text { EGDMA, Ethy } \\
\text { c } & \text { AM, Acrylam } \\
\text { d } & \text { 4-VP, 4-vinyl } \\
\text { e } & \text { DVB 80, Divi } \\
\text { f } & \text { TRIM, Trimet } \\
\text { g } & \text { DVB, Divinyl } \\
\text { h } & \text { PDA, Polydop }\end{array}$ & $\begin{array}{l}\text { crylicacid. } \\
\text { ylene glycol dime } \\
\text { ide. } \\
\text { lpyridine. } \\
\text { inylbenzene } 80 \text {. } \\
\text { thylolpropanetrin } \\
\text { lbenzene. } \\
\text { pamine. }\end{array}$ & methacrylate. & & & & & \\
\hline
\end{tabular}

mainly in organic and biological species. Brief summaries of different preparation methods for MIP syntheses and the applications of the MIP-based potentiometric sensors are shown in Tables 1 and 2, respectively. We hope to give the important research directions for future works. While the list of targets that can be detected is continuously growing, the bottleneck could be in the availability for the excellent MIP receptors with high binding strength and selectivity. However, advances made by numerous research groups all over the world allow us to conclude that the future of MIP-based potentiometric sensors is prospective.

\section{Declaration of competing interest}

The authors declare that they have no known competing financial interests or personal relationships that could have appeared to influence the work reported in this paper.

\section{Acknowledgments}

This work was financially supported by the National Natural Science Foundation of China (21677172, 21874151, 41576106), the National Key Research and Development Program of China (2016YFC1400700), the Youth Innovation Promotion Association of CAS (2014190) and the Taishan Scholar Program of Shandong Province (tspd20181215).

\section{References}

[1] E. Bakker, Y. Oin, Electrochemical sensors, Anal. Chem. 78 (2006) 3965-3984.

[2] E. Zdrachek, E. Bakker, Potentiometric sensing, Anal. Chem. 91 (2019) 2-26.

[3] J.B. Hu, A. Stein, P. Bühlmann, A disposable planar paper-based potentiometric ion-sensing platform, Angew. Chem. Int. Ed. 55 (2016) 7544-7547.
[4] P. Bühlmann, E. Pretsch, E. Bakker, Carrier-based ion-selective electrodes and bulk optodes. 2. Ionophores for potentiometric and optical sensors, Chem. Rev. 98 (1998) 1593-1687.

[5] E. Bakker, Electroanalysis with membrane electrodes and liquid-liquid interfaces, Anal. Chem. 88 (2016) 395-413.

[6] J.J. BelBruno, Molecularly imprinted polymers, Chem. Rev. 119 (2019) 94-119.

[7] R.J. Gui, H. Jin, H.J. Guo, Z.H. Wang, Recent advances and future prospects in molecularly imprinted polymers-based electrochemical biosensors, Biosens. Bioelectron. 100 (2018) 56-70.

[8] O.S. Ahmad, T.S. Bedwell, C. Esen, A. Garcia-Cruz, S.A. Piletsky, Molecularly imprinted polymers in electrochemical and optical sensors, Trends Biotechnol. 37 (2019) 294-309.

[9] A. Speltini, A. Scalabrini, F. Maraschi, M. Sturini, A. Profumo, Newest applications of molecularly imprinted polymers for extraction of contaminants from environmental and food matrices: a review, Anal. Chim. Acta 974 (2017) $1-26$.

[10] M.J. Whitcombe, I. Chianella, L. Larcombe, S.A. Piletsky, J. Noble, R. Porter, A. Horgan, The rational development of molecularly imprinted polymer-based sensors for protein detection, Chem. Soc. Rev. 40 (2011) 1547-1571.

[11] J. Wackerlig, P.A. Lieberzeit, Molecularly imprinted polymer nanoparticles in chemical sensing-Synthesis, characterisation and application, Sens. Actuators, B 207 (2015) 144-157.

[12] R.N. Liang, R.M. Zhang, W. Oin, Potentiometric sensor based on molecularly imprinted polymer for determination of melamine in milk, Sens. Actuators, B 141 (2009) 544-550.

[13] R.N. Liang, J.W. Ding S.S. Gao, W. Oin, Mussel-inspired surface-imprinted sensors for potentiometric label-free detection of biological species, Angew. Chem. Int. Ed. 56 (2017) 6833-6837.

[14] P.S. Sharma, A. Pietrzyk-Le, F. D'Souza, W. Kutner, Electrochemically synthesized polymers in molecular imprinting for chemical sensing, Anal. Bioanal. Chem. 402 (2012) 3177-3204

[15] A.H. Kamel, S.G. Mohammad, N.S. Awwad, Y.Y. Mohammed, Survey on the integration of molecularly imprinted polymers as artificial receptors in potentiometric transducers for pharmaceutical drugs, Int. J. Electrochem. Sci. 14 (2019) 2085-2124.

[16] J.M. Pan, W. Chen, Y. Ma, G.Q. Pan, Molecularly imprinted polymers as receptor mimics for selective cell recognition, Chem. Soc. Rev. 47 (2018) 5574-5587.

[17] J.E. Lofgreen, G.A. Ozin, Controlling morphology and porosity to improve performance of molecularly imprinted sol-gel silica, Chem. Soc. Rev. 43 (2014) 911-933.

[18] L.X. Chen, X.Y. Wang, W.H. Lu, X.Q. Wu, J.H. Li, Molecular imprinting: perspectives and applications, Chem. Soc. Rev. 45 (2016) 2137-2211. 
[19] L.X. Chen, S.F. Xu, J.H. Li, Recent advances in molecular imprinting technology: current status, challenges and highlighted applications, Chem. Soc. Rev. 40 (2011) 2922-2942.

[20] H. Zhang, R.Q. Yao, N. Wang, R.N. Liang, W. Qin, Soluble molecularly imprinted polymer-based potentiometric sensor for determination of bisphenol AF, Anal. Chem. 90 (2018) 657-662.

[21] Y. Ma, G.Q. Pan, Y. Zhang, X.Z. Guo, H.Q. Zhang, Comparative study of the molecularly imprinted polymers prepared by reversible additionfragmentation chain transfer "bulk" polymerization and traditional radical "bulk" polymerization, J. Mol. Recogn. 26 (2013) 240-251.

[22] A.S. Sacramento, F.T.C. Moreira, J.L. Guerreiro, A.P. Tavares, M.G.F. Sales, Novel biomimetic composite material for potentiometric screening of acetylcholine, a neurotransmitter in Alzheimer's disease, Mater. Sci. Eng. C 79 (2017) $541-549$.

[23] M.A. Hammam, H.A. Wagdy, R.M. El Nashar, Moxifloxacin hydrochloride electrochemical detection based on newly designed molecularly imprinted polymer, Sens. Actuators, B 275 (2018) 127-136.

[24] R.N. Liang, D.A. Song, R.M. Zhang, W. Qin, Potentiometric sensing of neutral species based on a uniform-sized molecularly imprinted polymer as a receptor, Angew. Chem. Int. Ed. 49 (2010) 2556-2559.

[25] S.A. Mohajeri, G. Karimi, J. Aghamohammadian, M.R. Khansari, Clozapine recognition via molecularly imprinted polymers; bulk polymerization versus precipitation method, J. Appl. Polym. Sci. 121 (2011) 3590-3595.

[26] L.B. Qi, R.N. Liang, W. Qin, Stimulus-responsive imprinted polymer-based potentiometric sensor for reversible detection of neutral phenols, Anal. Chem. 92 (2020) 4284-4291.

[27] T.T. Wang, R.N. Liang, T.J. Yin, R.Q. Yao, W. Qin, An all-solid-state imprinted polymer-based potentiometric sensor for determination of bisphenol S, RSC Adv. 6 (2016) 73308-73312.

[28] P.J. Li, R.N. Liang, X.F. Yang, W. Qin, Imprinted nanobead-based disposable screen-printed potentiometric sensor for highly sensitive detection of 2 naphthoic acid, Mater. Lett. 225 (2018) 138-141.

[29] J.W. Zhu, Y. Qin, Y.H. Zhang, Magnesium-selective ion-channel mimetic sensor with a traditional calcium ionophore, Anal. Chem. 82 (2010) 436-440.

[30] K. Eersels, P. Lieberzeit, P. Wagner, A review on synthetic receptors for bioparticle detection created by surface-imprinting techniques-from principles to applications, ACS Sens. 1 (2016) 1171-1187.

[31] M. Gast, H. Sobek, B. Mizaikoff, Advances in imprinting strategies for selective virus recognition a review, Trac. Trends Anal. Chem. 114 (2019) $218-232$.

[32] S. Ansari, S. Masoum, Molecularly imprinted polymers for capturing and sensing proteins: current progress and future implications, Trac. Trends Anal. Chem. 114 (2019) 29-47.

[33] F.Y. Cui, Z.R. Zhou, H.S. Zhou, Molecularly imprinted polymers and surface imprinted polymers based electrochemical biosensor for infectious diseases, Sensors 20 (2020) 996-1009.

[34] I. Basozabal, A. Guerreiro, A. Gomez-Caballero, M.A. Goicolea, R.J. Barrio, Direct potentiometric quantification of histamine using solid-phase imprinted nanoparticles as recognition elements, Biosens. Bioelectron. 58 (2014) $138-144$.

[35] E. Moczko, A. Guerreiro, E. Piletska, S. Piletsky, PEG-stabilized core-shell surface-imprinted nanoparticles, Langmuir 29 (2013) 9891-9896.

[36] E. Moczko, A. Poma, A. Guerreiro, I.P.D. Sansalvador, S. Caygill, F. Canfarotta, M.J. Whitcombe, S. Piletsky, Surface-modified multifunctional MIP nanoparticles, Nanoscale 5 (2013) 3733-3741.

[37] K. Smolinska-Kempisty, O.S. Ahmad, A. Guerreiro, K. Karim, E. Piletska, S. Piletsky, New potentiometric sensor based on molecularly imprinted nanoparticles for cocaine detection, Biosens. Bioelectron. 96 (2017) 49-54.

[38] S. Beyazit, B.T.S. Bui, K. Haupt, C. Gonzat, Molecularly imprinted polymer nanomaterials and nanocomposites by controlled/living radical polymerization, Prog. Polym. Sci. 62 (2016) 1-21.

[39] G.Q. Pan, Y. Zhang, Y. Ma, C.X. Li, H.Q. Zhang, Efficient one-pot synthesis of water-compatible molecularly imprinted polymer microspheres by facile RAFT precipitation polymerization, Angew. Chem. Int. Ed. 50 (2011) $11731-11734$.

[40] D. García-Mutio, A. Gómez-Caballero, A. Gotiandia, I. Larrauri, M.A. Goicolea, R.J. Barrio, Controlled grafting of molecularly imprinted films on gold microelectrodes using a self-assembled thiol iniferter, Electrochim. Acta 279 (2018) 57-65.

[41] R.D. Crapnell, A. Hudson, C.W. Foster, K. Eersels, B.V. Grinsven, T.J. Cleij, C.E. Banks, M. Peeters, Recent advances in electrosynthesized molecularly imprinted polymer sensing platforms for bioanalyte detection, Sensors 19 (2019) 1204-1231.

[42] R.S. Hutchins, L.G. Bachas, Nitrate-selective electrode developed by electrochemically mediated imprinting/doping of polypyrrole, Anal. Chem. 67 (1995) 1654-1660.

[43] E.M. Bomar, G.S. Owens, G.M. Murray, Nitrate ion selective electrode based on ion imprinted poly(N-methylpyrrole), Chemosensors 5 (2017) 2-9.

[44] D. Tonelli, B. Ballarin, L. Guadagnini, A. Mignani, E. Scavetta, A novel potentiometric sensor for L-ascorbic acid based on molecularly imprinted polypyrrole, Electrochim. Acta 56 (2011) 7149-7154.

[45] E. Bakker, P. Bühlmann, E. Pretsch, Carrier-based ion-selective electrodes and bulk optodes. 1. General characteristics, Chem. Rev. 97 (1997) 3083-3132.

[46] P. Bühlmann, L.D. Chen, Ion-selective electrodes with ionophore-doped sensing membranes, Supramol. Chem. (2012). https://doi.org/10.1002/ 9780470661345. smc097.
[47] T. Prasada Rao, R. Kala, Potentiometric transducer based biomimetic sensors for priority envirotoxic markers-An overview, Talanta 76 (2008) 485-496.

[48] J. Bobacka, A. Ivaska, A. Lewenstam, Potentiometric ion sensors, Chem. Rev. 108 (2008) 329-351.

[49] R.N. Liang, Q.W. Wang, W. Qin, Highly sensitive potentiometric sensor for detection of mercury in $\mathrm{Cl}^{-}$-rich samples, Sens. Actuators, B 208 (2015) $267-272$.

[50] J.H. Lei, J.W. Ding, Y. Chen, W. Qin, Potentiometric flow injection sensing system for determination of heparin based on current-controlled release of protamine, Anal. Chim. Acta 858 (2015) 60-65.

[51] J.W. Ding, Y. Gu, F. Li, H.X. Zhang, W. Qin, DNA nanostructure-based magnetic beads for potentiometric aptasensing, Anal. Chem. 87 (2015) 6465-6469.

[52] E. Pretsch, The new wave of ion-selective electrodes, Trac. Trends Anal. Chem. 26 (2007) 46-51.

[53] S.A. Ferguson, M.E. Meyerhoff, Advances in electrochemical and optical polyion sensing: a review, Sens. Actuators, B 272 (2018) 643-654.

[54] A. Hulanicki, R. Lewandowski, Some properties of ion-selective electrodes based on poly(vinyl chloride) membranes with liquid-ion-exchanger, Chem. Anal. 19 (1974) 53-60 (Warsaw, Pol.).

[55] B. Fu, E. Bakker, J.H. Yun, V.C. Yang, M.E. Meyerhoff, Response mechanism of polymer membrane-based potentiometric polyion sensors, Anal. Chem. 66 (1994) 2250-2259.

[56] W. Qin, R.N. Liang, X.L. Fu, Q.W. Wang, T.J. Yin, W.J. Song, Trace-level potentiometric detection in the presence of a high electrolyte background, Anal. Chem. 84 (2012) 10509-10513.

[57] Q.S. Ye, M.E. Meyerhoff, Rotating electrode potentiometry: lowering the detection limits of nonequilibrium polyion-sensitive membrane electrodes, Anal. Chem. 73 (2001) 332-336.

[58] R.N. Liang, L.J. Kou, Z.P. Chen, W. Qin, Molecularly imprinted nanoparticles based potentiometric sensor with a nanomolar detection limit, Sens. Actuators, B 188 (2013) 972-977.

[59] E. Jaworska, P. Pawłowski, A. Michalska, K. Maksymiuk, Advantages of amperometric readout mode of ion-selective electrodes under potentiostatic conditions, Electroanalysis 31 (2019) 343-349.

[60] E. Hupa, U. Vanamo, J. Bobacka, Novel ion-to-electron transduction principle for solid-contact ISEs, Electroanalysis 27 (2015) 591-594.

[61] E. Bakker, Enhancing ion-selective polymeric membrane electrodes by instrumental control, Trac. Trends Anal. Chem. 53 (2014) 98-105.

[62] G.A. Crespo, M. Cuartero, E. Bakker, Thin layer ionophore-based membrane for multianalyte ion activity detection, Anal. Chem. 87 (2015) 7729-7737.

[63] E. Zdrachek, E. Bakker, From molecular and emulsified ion sensors to membrane electrodes: molecular and mechanistic sensor design, Acc. Chem. Res. 52 (2019) 1400-1408.

[64] S. Makarychev-Mikhailov, A. Shvarev, E. Bakker, Pulstrodes: triple pulse control of potentiometric sensors, J. Am. Chem. Soc. 126 (2004) 10548-10549.

[65] E. Bakker, E. Pretsch, Modern potentiometry, Angew. Chem. Int. Ed. 46 (2007) 5660-5668.

[66] J.W. Ding, W. Qin, Current-Driven Ion fluxes of polymeric membrane ionselective electrode for potentiometric biosensing, J. Am. Chem. Soc. 131 (2009) 14640-14641.

[67] Y.D. Xu, E. Bakker, Ion channel mimetic potentiometric polymeric membrane ion sensor for surface-confined protein detection, Langmuir 25 (2009) 568-573.

[68] H.M.V. Oliveira, F.T.C. Moreira, M.G.F. Sales, Ciprofloxacin-imprinted polymeric receptors as ionophores for potentiometric transduction, Electrochim. Acta 56 (2011) 2017-2023.

[69] F.T.C. Moreira, A.H. Kamel, J.R.L. Guerreiro, M.G.F. Sales, Man-tailored biomimetic sensor of molecularly imprinted materials for the potentiometric measurement of oxytetracycline, Biosens. Bioelectron. 26 (2010) 566-574.

[70] F.T.C. Moreira, M.G.F. Sales, Biomimetic sensors of molecularly-imprinted polymers for chlorpromazine determination, Mater. Sci. Eng. C 31 (2011) 1121-1128.

[71] R. Gutiérrez-Climente, A. Gómez-Caballero, N. Unceta, M.A. Goicolea, R.J. Barrio, A new potentiometric sensor based on chiral imprinted nanoparticles for the discrimination of the enantiomers of the antidepressant citalopram, Electrochim. Acta 196 (2016) 496-504.

[72] H. Bagheri, A. Shirzadmehr, M. Rezaei, Designing and fabrication of new molecularly imprinted polymer-based potentiometric nano-graphene/ionic liquid/carbon paste electrode for the determination of losartan, J. Mol. Liq 212 (2015) 96-102.

[73] M.F. Abdel-Ghany, L.A. Hussein, N.F. El Azab, Novel potentiometric sensors for the determination of the dinotefuran insecticide residue levels in cucumber and soil samples, Talanta 164 (2017) 518-528.

[74] G. D'Agostino, G. Alberti, R. Biesuz, M. Pesavento, Potentiometric sensor for atrazine based on a molecular imprinted membrane, Biosens. Bioelectron. 22 (2006) 145-152.

[75] T. Ito, H. Radecka, K. Tohda, K. Odashima, Y. Umezawa, On the mechanism of unexpected potentiometric response to neutral phenols by liquid membranes based on quaternary ammonium salts systematic experimental and theoretical approaches, J. Am. Chem. Soc. 120 (1998) 3049-3059.

[76] L.J. Kou, R.N. Liang, X.W. Wang, Y. Chen, W. Qin, Potentiometric sensor for determination of neutral bisphenol A using a molecularly imprinted polymer as a receptor, Anal. Bioanal. Chem. 405 (2013) 4931-4936.

[77] R.N. Liang, L.S. Chen, W. Qin, Potentiometric detection of chemical vapors using molecularly imprinted polymers as receptors, Sci. Rep. 5 (2015) 12462.

[78] Y. Hoshino, H. Koide, T. Urakami, H. Kanazawa, T. Kodama, N. Oku, K.J. Shea, Recognition, neutralization, and clearance of target peptides in the 
bloodstream of living mice by molecularly imprinted polymer nanoparticles: a plastic antibody, J. Am. Chem. Soc. 132 (2010) 6644-6645.

[79] S. Ambrosini, S. Beyazit, K. Haupt, B.T.S. Bui, Solid-phase synthesis of molecularly imprinted nanoparticles for protein recognition, Chem. Commun. 49 (2013) 6746-6748

[80] C. Branger, W. Meouche, A. Margaillan, Recent advances on ion-imprinted polymers, React. Funct. Polym. 73 (2013) 859-875.

[81] G.M. Murray, A.L. Jenkins, A. Bzhelyansky, O.M. Uy, Molecularly imprinted polymers for the selective sequestering and sensing of ions, Johns Hopkins APL Tech. Dig. 18 (1997) 464-472.

[82] R.N. Liang, R.M. Zhang, W.J. Song, X.F. Hu, W. Qin, Potentiometric sensor based on an ion-imprinted polymer for determination of copper, Sens. Lett. 9 (2011) $557-562$.

[83] M. Shamsipur, B. Hashemi, S. Dehdashtian, M. Mohammadi, M.B. Gholivand, A. Garau, V. Lippolis, Silver ion imprinted polymer nanobeads based on a azathioether crown containing a 1,10-phenanthroline subunit for solid phase extraction and for voltammetric and potentiometric silver sensors, Anal. Chim. Acta 852 (2014) 223-235.

[84] A. Shirzadmehr, A. Afkhami, T. Madrakian, A new nano-composite potentiometric sensor containing an $\mathrm{Hg}^{2+}$-ion imprinted polymer for the trace determination of mercury ions in different matrices, J. Mol. Liq. 204 (2015) 227-235.

[85] T. Rosatzin, L.I. Andersson, W. Simon, K. Mosbach, Preparation of $\mathrm{Ca}^{2+}$ selective sorbents by molecular imprinting using polymerisable ionophores, J. Chem. Soc., Perkin Trans. 2 (1991) 1261-1265.

[86] J.Q. Fu, L.X. Chen, J.H. Li, Z. Zhang, Current status and challenges of ion imprinting, J. Mater. Chem. A 3 (2015) 13598-13627.

[87] X.Q. Cai, J.H. Li, Z. Zhang, F.F. Yang, R.C. Dong, L.X. Chen, Novel $\mathrm{Pb}^{2+}$ ion imprinted polymers based on ionic interaction via synergy of dual functiona monomers for selective solid-phase extraction of $\mathrm{Pb}^{2+}$ in water samples, ACS Appl. Mater. Interfaces 6 (2014) 305-313.

[88] S.F. Xu, L.X. Chen, J.H. Li, Y.F. Guan, H.Z. Lu, Novel $\mathrm{Hg}^{2+}$-imprinted polymers based on thymine- $\mathrm{Hg}^{2+}$-thymine interaction for highly selective preconcentration of $\mathrm{Hg}^{2+}$ in water samples, J. Hazard Mater. 237-238 (2012) 347-354.

[89] M.A.C. Stuart, W.T.S. Huck, J. Genzer, M. Müller, C. Ober, M. Stamm, G.B. Sukhorukov, I. Szleifer, V.V. Tsukruk, M. Urban, F. Winnik, S. Zauscher, I. Luzinov, S. Minko, Emerging applications of stimuli-responsive polymer materials, Nat. Mater. 9 (2010) 101-113.

[90] L. Hu, Q. Zhang, X. Li, M.J. Serpe, Stimuli-responsive polymers for sensing and actuation, Mater. Horiz. 6 (2019) 1774-1776.

[91] W. Chen, Y. Ma, J.M. Pan, Z.H. Meng, G.O. Pan, B. Sellergren, Molecularly imprinted polymers with stimuli-responsive affinity: progress and perspectives, Polymers 7 (2015) 1689-1715.

[92] Y. Ma, Y. Zhang, M. Zhao, X.Z. Guo, H.Q. Zhang, Efficient synthesis of narrowly dispersed molecularly imprinted polymer microspheres with multiple stimuli-responsive template binding properties in aqueous media, Chem. Commun. 48 (2012) 6217-6219.

[93] Z. Liu, H. He, Synthesis and applications of boronate affinity materials: from class selectivity to biomimetic specificity, Acc. Chem. Res. 50 (2017) 2185-2193.

[94] A.H. Kamel, X.J. Jiang, P.J. Li, R.N. Liang, A paper-based potentiometric sensing platform based on molecularly imprinted nanobeads for determination of bisphenol A, Anal. Methods 10 (2018) 3890-3895.

[95] J. Kim, I. Jeerapan, J.R. Sempionatto, A. Barfidokht, R.K. Mishra, A.S. Campbell, L.J. Hubble, J. Wang, Wearable bioelectronics: enzyme-based body-worn electronic devices, Acc. Chem. Res. 51 (2018) 2820-2828.

[96] J. Kim, A.S. Campbell, B.E.F. de Ávila, J. Wang, Wearable biosensors for healthcare monitoring, Nat. Biotechnol. 37 (2019) 389-406.

[97] M. Parrilla, M. Cuartero, G.A. Crespo, Wearable potentiometric ion sensors, Trac. Trends Anal. Chem. 110 (2019) 303-320.

[98] R.K. Mishra, A. Barfidokht, A. Karajic, J.R. Sempionatto, J. Wang, J. Wang, Wearable potentiometric tattoo biosensor for on-body detection of G-type nerve agents simulants, Sens. Actuators, B 273 (2018) 966-972. 